\title{
Robo1 and Robo2 Cooperate to Control the Guidance of Major Axonal Tracts in the Mammalian Forebrain
}

\author{
Guillermina López-Bendito, ${ }^{1}$ Nuria Flames, ${ }^{1}$ Le Ma, ${ }^{2}$ Coralie Fouquet, ${ }^{3,4}$ Thomas Di Meglio, ${ }^{3,4}$ Alain Chedotal, ${ }^{3,4}$ \\ Marc Tessier-Lavigne, ${ }^{2,5}$ and Oscar Marín ${ }^{1}$ \\ ${ }^{1}$ Instituto de Neurociencias de Alicante, Consejo Superior de Investigaciones Científicas and Universidad Miguel Hernández, 03550 Sant Joan d’Alacant, \\ Spain, ${ }^{2}$ Howard Hughes Medical Institute, Department of Biological Sciences, Stanford University, Stanford, California $94305,{ }^{3}$ Centre National de la \\ Recherche Scientifique, Unité Mixte de Recherche (UMR) 7102, and ${ }^{4}$ Université Pierre et Marie Curie-Paris 6, UMR 7102, 75005 Paris, France, and \\ ${ }^{5}$ Genentech, Inc., South San Francisco, California 84080
}

The function of the nervous system depends on the precision of axon wiring during development. Previous studies have demonstrated that Slits, a family of secreted chemorepellent proteins, are crucial for the proper development of several major forebrain tracts. Mice deficient in Slit2 or, even more so, in both Slit1 and Slit2 have defects in multiple axonal pathways, including corticofugal, thalamocortical, and callosal connections. In the spinal cord, members of the Robo family of proteins help mediate the function of Slits, but the relative contribution of these receptors to the guidance of forebrain projections remains to be determined. In the present study, we addressed the function of Robol and Robo2 in the guidance of forebrain projections by analyzing Robo1-, Robo2-, and Robo1;Robo2deficient mice. Mice deficient in Robo2 and, more dramatically, in both Robo1 and Robo2, display prominent axon guidance errors in the development of corticofugal, thalamocortical, and corticocortical callosal connections. Our results demonstrate that Robo1 and Robo2 mostly cooperate to mediate the function of Slit proteins in guiding the major forebrain projections.

Key words: axon guidance; cortex; repulsion; Robo; Slit; midline; thalamocortical

\section{Introduction}

The development of the major axonal projections in the mammalian forebrain has been extensively studied in the recent years (for review, see López-Bendito and Molnár, 2003; Richards et al., 2004; Price et al., 2006). Among them, the reciprocal connections between the cortex and the thalamus, corticocortical projections linking both cerebral hemispheres through the corpus callosum, and corticofugal projections directed toward the mesencephalon, pons, and spinal cord have received much attention. These connections underlie some of the most essential functions of the mammalian cerebral cortex, such as perception and motor behavior.

\footnotetext{
Received 0ct. 24, 2006; revised Feb. 15, 2007; accepted Feb. 19, 2007

This work was supported by grants from Spanish Government (BFU2005-04773/BMC) and the European Young Investigator (EURYI) program (0.M.) and from Association pour la Recherche sur le Cancer (A.C.). G.L.-B. is a "Ramón y Cajal" Investigator from the Consejo Superior de Investigaciones Científicas. N.F. was supported by a Formación de Profesorado Universitario fellowship from the Spanish Ministry of Education and Science. 0.M. is a European Molecular Biology Organization Young Investigator, a National Alliance for Research in Schizophrenia and Depression Young Investigator, and an EURYI Awardee. We thank M. Pérez for excellence technical assistance, T. Gil and M. Bonete for daily technical support in the laboratory, and Fujio Murakami for Rob01 and Robo2 antibodies. We also thank members from the Marín and Rico laboratories for useful discussions and comments.

Correspondence should be addressed to Dr. Oscar Marín, Instituto de Neurociencias de Alicante, Consejo Superio de Investigaciones Científicas and Universidad Miguel Hernández, 03550 Sant Joan d'Alacant, Spain. E-mail: o.marin@umh.es.

L. Ma's present address: Department of Cell and Neurobiology, Zilkha Neurogenetic Institute, Keck School of Medicine, University of Southern California, Los Angeles, CA 90089.

N. Flames' present address: Department of Biochemistry and Molecular Biophysics, Columbia University, New York, NY 10032.

DOI:10.1523/JNEUROSCI.4605-06.2007

Copyright $\odot 2007$ Society for Neuroscience $\quad$ 0270-6474/07/273395-13\$15.00/0
}

Several guidance molecules have been shown to influence the development of these major forebrain connections. For example, Netrin1 is required for the formation of the corpus callosum (Serafini et al., 1996), and it has also been shown to influence the development of corticofugal (Métin et al., 1997; Richards et al., 1997) and thalamocortical projections (Braisted et al., 2000). Similarly, EphA/ephrinA signaling appears to underlie the topographic organization of thalamocortical projections (Dufour et al., 2003; Torii and Levitt, 2005). In addition, Slits have been shown to play a fundamental role in the guidance of all three major forebrain connections (corticocortical, corticofugal, and thalamocortical) in the mammalian forebrain (Bagri et al., 2002).

Slit proteins have been implicated in axon guidance of insects, nematodes, and vertebrates, contributing through different mechanisms to the development of multiple axonal projections. In addition to playing a major role in regulating axon crossing at the midline (Kidd et al., 1999; Long et al., 2004), Slits specify the lateral and dorsoventral positioning of longitudinal axonal pathways (Rajagopalan et al., 2000; Simpson et al., 2000; Bagri et al., 2002; Nguyen Ba-Charvet et al., 2002; Long et al., 2004) and contribute to the formation of commissures by channeling axons into particular regions (Bagri et al., 2002; Hutson and Chien, 2002; Plump et al., 2002; Shu et al., 2003).

As in Drosophila (Kidd et al., 1999) and Caenorhabditis elegans (Hao et al., 2001), the function of Slit proteins in the vertebrate nervous system is primarily mediated by Robo receptors (Brose et al., 1999; Li et al., 1999; Yuan et al., 1999; Hutson and Chien, 2002; Long et al., 2004; Sabatier et al., 2004). In the mammalian 
spinal cord, Robo1, Robo2, and the Robo family protein Rig1/ Robo3 cooperate to mediate the function of Slit proteins in the guidance of commissural axons (Long et al., 2004; Sabatier et al., 2004). In the developing forebrain, the expression pattern of Robo1 and Robo2 strongly suggest their involvement in the guidance of corticocortical, corticothalamic, and corticofugal projections (Marillat et al., 2001; Bagri et al., 2002; Whitford et al., 2002; Sundaresan et al., 2004). Accordingly, a recent study has shown that Robol plays a role in the development of some of these pathways, most notably in the formation of corticocortical callosal projections (Andrews et al., 2006).

Here, we investigated the function of Robo1 and Robo2 in the formation of forebrain connections by analyzing mice carrying severe loss-of-function alleles for Robo1, Robo2, or both Robo1 and Robo 2 receptors. Our results demonstrate that Robol and Robo2 mostly cooperate to control the development of the major axonal tracts in the mammalian forebrain. The resemblance of the axonal defects found in Robo1;Robo2 and Slit1;Slit2 double mutants strongly suggests that Robol and Robo2 mediate the function of Slit 1 and Slit 2 in the formation of these connections.

\section{Materials and Methods}

Animals. Mice were treated according to protocols approved by the Committee on Animal Research at the University Miguel Hernández, following Spanish and European Union regulations. Embryonic day 13.5 (E13.5), E14.5, and E18.5 embryos were obtained by mating Robo1 ${ }^{+/-}$, $\mathrm{Robo2}^{+/-}$, or Robo1 ${ }^{+/-} ; \mathrm{Robo2}^{+/-}$mice, which were maintained in CD1, C57BL/6, and mixed CD1-C57BL/6 backgrounds, respectively. Genotyping was performed by PCR as described previously (Grieshammer et al., 2004; Long et al., 2004). Because the Robo1 and Robo2 genes are linked (being separated by only $1.8 \mathrm{Mb}$ ), the Robo1 ${ }^{+/-} ; R_{0 b o 2^{+/-}}$colony was generated through meiotic recombination of the mutant alleles ( $Z$. Chen B. B. Gore, H. Long, L. Ma, and M. Tessier-Lavigne, unpublished observations).

Immunohistochemistry and in situ hybridization. Embryos were obtained by cesarean section, anesthetized by cooling, perfused with $4 \%$ paraformaldehyde (PFA) in PBS, and postfixed in PFA for 2-8 h. After postfixation, brains were cryoprotected in $30 \%$ sucrose and either frozen in embedding medium and cut in a cryostat [embryonic day 13.5 (E13.5) and E14.5] or frozen and cut in a freezing sliding microtome (E16.5 and E18.5). Immunohistochemistry was performed on $40-\mu \mathrm{m}$-thick freefloating sections (E16.5 and E18.5) or on 20- $\mu$ m-thick cryostat sections mounted onto glass slides (E13.5 and E14.5). Free-floating sections were preincubated in $5 \%$ normal serum of the species in which the secondary antibody was raised, $1 \%$ BSA, and $0.3 \%$ Triton X-100 in PBS for $1 \mathrm{~h}$ at room temperature, and subsequently incubated with the primary antiserum for $24-36 \mathrm{~h}$ at $4^{\circ} \mathrm{C}$ in $2 \%$ normal serum and $0.3 \%$ Triton $\mathrm{X}-100$ in PBS. The following antibodies were used: rabbit polyclonal antibody against Robol (diluted 1:1000; kindly provided by Fujio Murakami, Osaka University, Osaka, Japan), rabbit polyclonal antibody against Robo2 (diluted 1:1000; kindly provided by Fujio Murakami), rat polyclonal antibody against L1 (Chemicon, Temecula, CA; diluted 1:200), rabbit anti-green fluorescent protein (Invitrogen, San Diego, CA; 1:1000), rabbit anti-calbindin (Swant, Bellinzona, Switzerland; 1:5000), rabbit anti-calretinin (Chemicon; 1:5000), and rabbit anti-Neuropeptide Y (NPY) (DiaSorin, Stillwater, MN; 1:3000). Sections were then incubated in biotinylated secondary antibodies (Vector Laboratories, Burlingame, CA; 1:200), and then transferred into avidin-biotin-peroxidase complex (ABC kit; Vector Laboratories; 1:200) for $2 \mathrm{~h}$ at room temperature. Peroxidase enzyme activity was revealed using 3,3'diaminobenzidine tetrahydrochloride $[0.05 \%$ in phosphate buffer $(\mathrm{PB})$, $\mathrm{pH}$ 7.4] as chromogen and $0.01 \% \mathrm{H}_{2} \mathrm{O}_{2}$ as substrate. Sections were rinsed, dehydrated and mounted in Eukitt mounting media (Electron Microscopy Sciences, Fort Washington, PA). In each experiment, sections from homozygous mutants and their wild-type and heterozygous littermates were processed together. In control experiments, the primary antibody was replaced by $0.2 \%$ Triton X-100 in PB, and then reacted as above. These control sections showed no positive immunoreactivity. Photomicrographs were prepared by light microscopy and documented using a Leica (Nussloch, Germany) DC 500 digital camera. Immunohistochemistry was performed on cryostat sections on glass slides using essentially the same protocol. In some cases, immunofluorescence labeling using fluorochrome-conjugated secondary antibodies was performed on $40 \mu \mathrm{m}$ free-floating sections. DNA counterstaining was performed with bis-benzimide $(2.5 \mu \mathrm{g} / \mathrm{ml}$ in PBS; Invitrogen), and the slides were mounted using Prolong Antifade (Invitrogen). For in situ hybridization, $20-\mu \mathrm{m}$-thick cryostat sections were hybridized with digoxigenin-labeled probes essentially as described previously (Schaeren-Wiemers and Gerfin-Moser, 1993), using cDNA probes for Robo1 and Robo2 (Bagri et al., 2002).

Slit-alkaline phosphatase binding. Human LRR2-Slit1-alkaline phosphatase (AP), human LRR2-Slit2-AP, or control AP constructs were transfected in COS cells. After $2 \mathrm{~d}$, the conditioned media were concentrated and used directly for binding assays as described previously (Kolodkin et al., 1997). Briefly, $20 \mu \mathrm{m}$ cryostat sections from wild-type, Robo1 $^{-1-}$, Robo $^{-/-}$, and Robo1;Robo2 double-mutant brains were fixed $8 \mathrm{~min}$ in cooled $100 \%$ methanol. After that, sections were washed in $1 \times$ PBS, $4 \mathrm{~mm} \mathrm{MgCl}_{2}$, and incubated in a blocking solution $(1 \times \mathrm{PBS}, 4 \mathrm{~mm}$ $\mathrm{MgCl}_{2}, 10 \% \mathrm{FBS}$ ) for $1 \mathrm{~h}$ at room temperature. For the binding step, Slit-AP fusion proteins were diluted from $1 / 5$ to $1 / 10$ in $1 \times$ PBS and incubated for $2 \mathrm{~h}$ at room temperature. After washes in $1 \times \mathrm{PBS}, 4 \mathrm{~mm}$ $\mathrm{MgCl}_{2}$, the bound ligand was fixed to sections with a solution containing $60 \%$ acetone, $4 \%$ paraformaldehyde, and 20 mM HEPES, $\mathrm{pH}$ 7.0. Then, sections were treated at $65^{\circ} \mathrm{C}$ for $2 \mathrm{~h}$ in $1 \times \mathrm{PBS}$ to inactivate endogenous phosphatases. Finally, the slices were incubated in revelation buffer $(100$ mм Tris, pH 9.5, $100 \mathrm{~mm} \mathrm{NaCl}, 5 \mathrm{~mm} \mathrm{MgCl}_{2}, 300 \mathrm{mg} / \mathrm{ml}$ nitroblue tetrazolium, and $250 \mathrm{mg} / \mathrm{ml}$ 5-bromo-4-chloro-3-indolyl phosphate) for $2 \mathrm{~h}$ at room temperature.

Quantification of axonal length. Neocortical and dorsal thalamic explants were dissected from E17.5 and E13.5 wild-type mice, respectively, and cultured in collagen for up to $96 \mathrm{~h}$. Explants were confronted with COS cells aggregates transfected with $d s R e d$ or cotransfected with Slit2 and $d s R e d$. After fixation, dorsal thalamus explants were subdivided into four sectors and the length of the 13 longest axons was measured in every explant using SigmaScan Pro software.

Axon tracing. Axon tracing was performed on E14.5 and E18.5 mouse brains after perfusion. Brains were then postfixed by overnight immersion in $4 \% \mathrm{PFA}$ at $4^{\circ} \mathrm{C}$. For neocortical injections, large crystals of $1,1^{\prime}-$ dioctadecyl 3,3,3'3'-tetramethylindocarbocyanine perchlorate (DiI) (Invitrogen) were placed into the parietal cortex of E14.5 and E18.5 brains. For dorsal thalamic injections, the brains were bisected into hemispheres, each of which was used for a separate experiment. Small crystals of DiI (0.1-0.3 mm diameter) were injected into the medial face of dorsal thalamus with an insect pin. The depth to which the crystal was inserted into the thalamus or the cortex was $\sim 0.5-1 \mathrm{~mm}$ from the midline. The brains were then incubated in $4 \%$ PFA for $2-4$ weeks at $37^{\circ} \mathrm{C}$, rinsed in $0.1 \mathrm{M} \mathrm{PB}, \mathrm{pH} 7.4$, and embedded in $4 \%$ low-melt agarose. Fiftyto $100-\mu \mathrm{m}$-thick sections were then cut on a vibratome (Leica VT 1000S) in the coronal plane and subsequently counterstained with bisbenzimide, coverslipped with Aquamount (BDH, Poole, UK), and photographed in a fluorescence microscope equipped with a Leica DC500 digital camera.

\section{Results \\ Expression of Robol and Robo2 receptors in the developing forebrain}

To investigate the role of Robo receptors in axon guidance in the forebrain, we first analyzed their expression pattern focusing on regions and developmental stages where the major axonal tracts navigate and develop. Consistent with previous studies (Marillat et al., 2001; Bagri et al., 2002; Whitford et al., 2002; Sundaresan et al., 2004), Robol and Robo 2 mRNA are highly expressed in the dorsal thalamus and the cerebral cortex at the time when corticofugal and thalamocortical projections form (Fig. $1 A, D$ ). Interestingly, the pattern of expression of Robo1 and Robo2 mRNA 


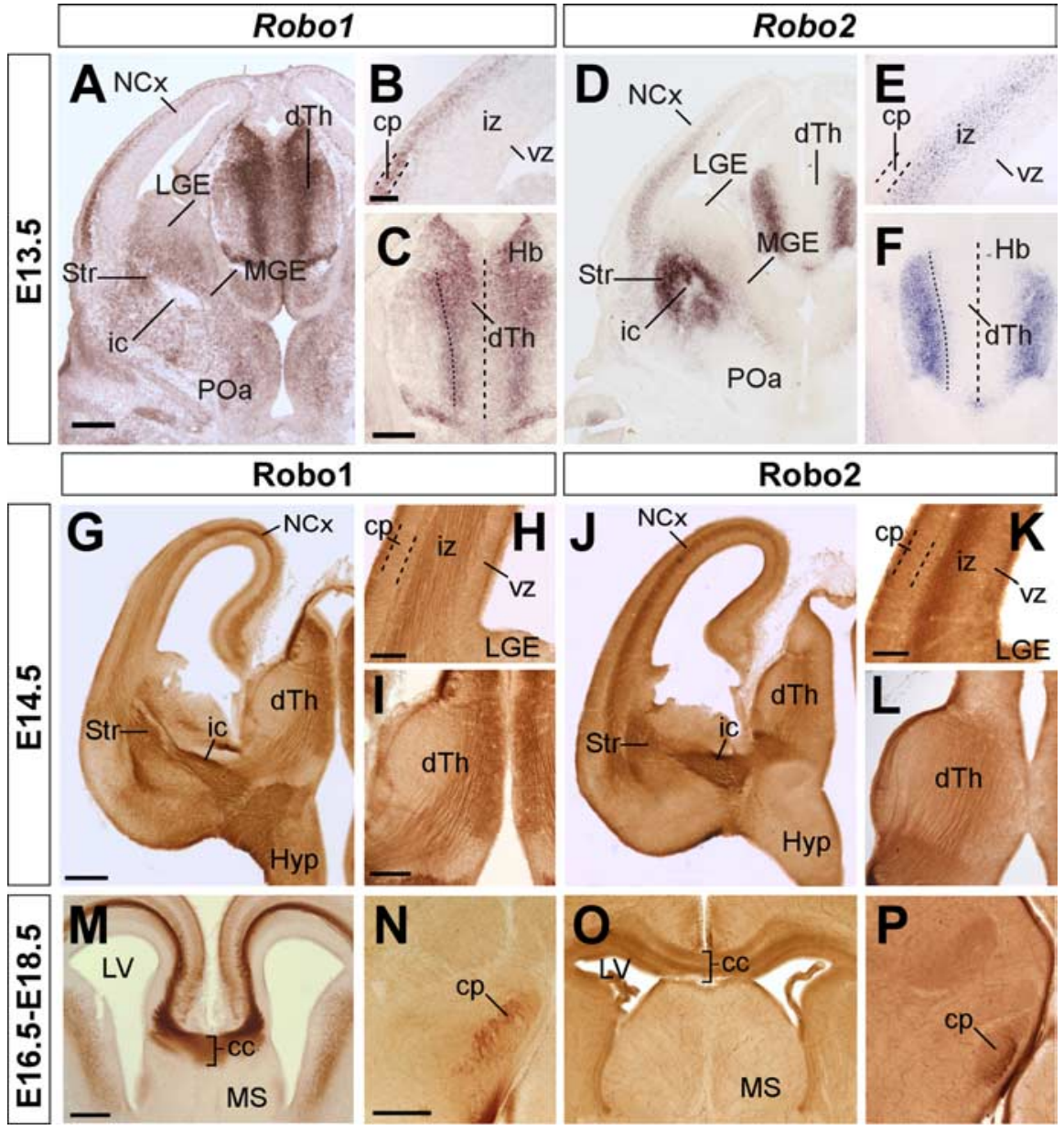

Figure 1. Expression of Robo1 and Robo2 receptors in the embryonic mouse forebrain. Serial coronal sections through midtelencephalic/rostral diencephalic levels of an E13.5 embryo showing the expression of Robo1 and Robo2 mRNAs (A-D), and of E14.5, E16.5, and E18.5 embryos showing the expression of Robo1 $(\mathbf{G}-\mathbf{I}, \mathbf{M}, \mathbf{N})$ and Robo2 proteins $(\boldsymbol{J}-\mathbf{L}, \mathbf{0}, \boldsymbol{P})$. Robo1 and Robo2 mRNAs are expressed in the neocortex (NCx) and dorsal thalamus (dTh) in a partially complementary manner. Robo1 is expressed in the cortical plate $(\boldsymbol{c p})(\boldsymbol{A}, \boldsymbol{B})$, in a gradient decreasing from lateral to medial cortex, as well as in the dTh, in a gradient decreasing from the neuroepithelium to the mantle $(\boldsymbol{A}, \boldsymbol{C})$. Robo2 is expressed in the subplate and intermediate zone (iz) of the cortex $(\boldsymbol{D}, \boldsymbol{E})$ and in the most superficial region of the $\mathrm{dTh}(\boldsymbol{D}, \boldsymbol{F})$. Coronal sections through E14.5, E16.5, and E18.5 brains showing Robo1 (G-I, $\boldsymbol{M}, \boldsymbol{N})$ and Robo2 $(\boldsymbol{J}-\mathbf{L}, \mathbf{O}, \boldsymbol{P})$ protein expression pattern are shown. Robo1 and Rob02 receptors are expressed in developing axons localized at the iz of the cortex $(\boldsymbol{G}, \boldsymbol{H}, \boldsymbol{J}, \boldsymbol{K})$, dorsal thalamus $(\boldsymbol{I}, \mathbf{L})$, and corpus callosum $(\mathbf{c c})(\boldsymbol{M}, \mathbf{0})$, and in the cerebral peduncle (cp) $(\boldsymbol{N})$. ic, Internal capsule; Hb, habenula; vz, ventricular zone; Str, striatum; LGE, lateral ganglionic eminence; MGE, medial ganglionic eminence; $M S$, medial septum; LV, lateral ventricle; Hyp, hypothalamus; POa, anterior preoptic area. Scale bars: $\boldsymbol{A}, \boldsymbol{D}, \mathbf{G}, \mathbf{J}, 300$ $\mu \mathrm{m} ; \boldsymbol{B}, \boldsymbol{E}, \boldsymbol{H}, \boldsymbol{K}, \boldsymbol{M}, \mathbf{0}, 100 \mu \mathrm{m} ; \boldsymbol{C}, \boldsymbol{F}, \mathbf{I}, \mathbf{L}, \mathbf{N}, \boldsymbol{P}, 200 \mu \mathrm{m}$.

appears mostly complementary, both in the developing cortex (Fig. $1 B, E$ ) and dorsal thalamus (Fig. $1 C, F$ ). Specifically, cells at the intermediate zone of the developing cortex appear to express Robo2 (Fig. $1 E$ ), whereas neurons that begin to accumulate in the cortical plate primarily express Robo1 (Fig. $1 B$ ). Conversely, dorsal thalamic neurons predominantly express Robo1 as they first become postmitotic (Fig. 1C), but they mostly express Robo2 once they start to differentiate into distinct nuclei of the dorsal thalamus (Fig. $1 F$ ).

Despite these apparent differences at the mRNA level, immunohistochemistry against Robo1 and Robo2 demonstrated that axons in both corticofugal and thalamocortical projections express both receptors (Fig. 1G-L). Moreover, both receptors are also expressed in corticospinal (Fig. $1 N, P$ ) (for simplicity, we use through the text the term "corticospinal" to refer to cortical layer 5 projections directed toward the mesencephalon, pons, and spinal cord) and callosal projections (Fig. $1 \mathrm{M}, \mathrm{O}$ ). In agreement with these results, analysis of Slit binding sites using Slit1 and Slit2 probes fused to AP tags revealed that callosal, thalamocortical, corticothalamic, and corticospinal axons contain receptors that bind both Slit1 and Slit2 (Fig. 2A-D) (data not shown). Slit-AP binding was also detected in the absence of either one of the Robo receptors, reinforcing the notion that Robol and Robo2 are mostly coexpressed in these projections (Fig. 2E,F) (data not shown). In contrast, Slit2-AP probes did not stain callosal, thalamocortical, corticothalamic, or corticospinal axons in tissue obtained from Robo1;Robo2 double mutants (Fig. 2H) (data not shown), whereas Slit1-AP probes revealed only slight staining in some of these fibers tracts (Fig. 2G) (data not shown).

In summary, the temporal and spatial pattern of Robo1 and Robo2 expression in cortical and dorsal thalamic axons suggest that these receptors may play a role in the guidance of the major forebrain axonal tracts, probably mediating the function of Slit proteins in this process.

\section{Slit2 repels neocortical and dorsal thalamic axons in vitro}

The previous results strongly suggest that cortical and thalamic axons respond to Slit proteins through both Robol and Robo2 receptors. In agreement with this view, it has been previously shown that cortical axons are repelled by Slit 2 in vitro (Shu and Richards, 2001) (supplemental Fig. 1, available at www.jneurosci.org as supplemental material). However, the effect of Slits on thalamic axons has not been tested. To examine the role of Slit proteins on thalamic axons, we cocultured E13.5 dTh explants with COS cells aggregates expressing Slit2 in three-dimensional collagen gels (Fig. 3). After $4 \mathrm{~d}$ in vitro, axons extended radially from explants in control experiments (Fig. $3 A, D)(n=19)$. In contrast, axon length was significantly shorter on the side of explants facing COS cells aggregates expressing Slit2 (Fig. $3 B, D)(n=22)$. Moreover, we observed many axons turning away from COS cells aggregates expressing Slit2 (Fig. $3 B$, arrow). These results suggest that, as in the case of cortical axons, Slits proteins also repel the growth of dorsal thalamic axons.

\section{Abnormal corticospinal and thalamocortical projections in Robo2 but not Robo1 mutants}

The mostly complementary protein expression pattern of Robol and Robo2 in the developing forebrain axons suggests that these receptors may coordinate their activity in the guidance of cortical and thalamic projections. To directly address the role of individual Robo receptors in the guidance of these axonal tracts, we first examined the organization of these axons in mice carrying lossof-function alleles of Robo1 or Robo2. At E18.5, when most forebrain connections have been established, immunohistochemistry 



Figure 2. Coronal sections through the forebrain of E18.5 wild-type $(\boldsymbol{A}-\boldsymbol{D}), \operatorname{Rob01}(\boldsymbol{E})$, Robo2 $(\boldsymbol{F})$, and Robo1;Robo2 double-mutant $(\boldsymbol{G}, \boldsymbol{H})$ fetuses showing Slit1-AP binding $(\boldsymbol{A}, \boldsymbol{B}, \boldsymbol{G})$ and Slit2-AP binding $(\boldsymbol{E}, \boldsymbol{F}, \boldsymbol{H}) . \boldsymbol{A}-\boldsymbol{D}, \mathrm{AP}$ staining labels corticocortical axons at the corpus callosum (cC) $(A, C)$, corticospinal axons at the cerebral peduncle (CP) (D), and thalamocortical/corticothalamic projections $(\boldsymbol{B}) . \boldsymbol{E}, \boldsymbol{F}$, Slit2-AP staining identifies corticocortical callosal projections in Robo1 $(\boldsymbol{E})$ and Robo2 $(\boldsymbol{F})$ mutant brains. Some ectopic bundles are abnormally displaced at the corpus callosum (cc) of Robo1 mutants ( $\boldsymbol{E}$, arrows). $\mathbf{G}, \boldsymbol{H}$, Slit-AP binding assays do not generally stain any axonal tract in the forebrain of Robo 1;Robo2 double mutants. Only in a few cases, very weakly stained fibers could be observed after Slit1-AP binding ( $G$, arrows). H, Hippocampus; Str, striatum; NCX, neocortex; SE, septum; dTh, dorsal thalamus; GP, globus pallidus; Hyp, hypothalamus. Scale bars: $\boldsymbol{A}, \boldsymbol{C}, \boldsymbol{E}, \boldsymbol{F}, 500 \mu \mathrm{m} ; \boldsymbol{B}, \boldsymbol{G}, \boldsymbol{H}, 1 \mathrm{~mm} ; \boldsymbol{D}, 200 \mu \mathrm{m}$.

for the cell adhesion molecule L1 labels both corticothalamic and thalamocortical axons as they course through the internal capsule in the basal ganglia (Fig. 4A) (Jones et al., 2002; López-Bendito et al., 2002). The distribution of $\mathrm{L} 1+$ fibers in the telencephalon of Robo1 or Robo2 single mutants was mostly indistinguishable from control mice ( $n=8$ for each genotype) (Fig. $4 A-C$ ). Moreover, labeling of axons with DiI crystals placed in the neocortex of E18.5 Robo1 or Robo2 single mutants did not reveal major differences in the distribution of corticofugal axons as they course through the internal capsule (Fig. 5A-C). In some Robo2 mutants, however, a few corticofugal axons were found ventrally displaced, abnormally reaching the ventral midline at the level of the anterior commissure ( $n=4$ of 8 brains) (Fig. $\left.5 C^{\prime}\right)$.

Immunohistochemistry for NPY, a transient marker of corticothalamic projections (Bagri et al., 2002), did not reveal major differences in the distribution of corticothalamic axons in either Robo1 or Robo 2 single mutants ( $n=4$ for each genotype) (Fig. $4 D-F$ ). Similar results were obtained from the analysis of corticothalamic axons after DiI placements in the neocortex $(n=8$ for each genotype) (Fig. $5 D, E$ ) (data not shown). Occasionally, some abnormal bundles of cortical fibers were found in the dorsal thalamus of Robo 2 mutants ( $n=4$ of 8 brains) (Fig. $5 F$ ), suggesting the existence of targeting defects in a subset of mice lacking Robo2 function.

Because the development of corticothalamic and thalamocortical axons is highly coordinated in time and space (for review, see López-Bendito and Molnár, 2003), we next analyzed thalamocortical projections in Robo1 and Robo2 single mutants. Analysis of thalamocortical projections using immunohistochemistry against calretinin, a marker of thalamic axons, revealed a normal distribution of thalamocortical axons in Robol mutants compared with controls $(n=4)$ (Fig. $4 G, H)$ (data not shown). In contrast, in Robo 2 mutants, some thalamocortical fibers were observed to fail reaching the telencephalon, and instead growing abnormally toward the ventral diencephalon, a region normally nonpermissive for thalamocortical axon outgrowth $(n=4)$ (Fig. 4I) (Braisted et al., 1999). DiI injections in the dorsal thalamus of control, Robo1 and Robo2 mutants confirmed that numerous thalamocortical axons failed to enter the telencephalon and instead invaded the hypothalamus in Robo2 mutants (Fig. 5I), whereas no major defects were observed in the guidance of thalamocortical axons in Robol mutants compared with wildtype control brains $(n=4)$ (Fig. $5 G, H)$.

We next studied the organization of other corticofugal projections, such as those contributing to cerebral peduncle or the corpus callosum. Analysis of the cerebral peduncle at the level of the diencephalon demonstrated that corticospinal axons develop normally in the absence of Robol function compared with wildtype controls $(n=4)$ (Figs. $4 J, K, 5 J, K)$. In contrast, the cerebral peduncle appears to be ventrally displaced in all Robo 2 mutants examined $(n=4)$ (Figs. $4 L, 5 L)$. Moreover, DiI-labeled corticofugal axons were observed to abnormally defasciculate from the cerebral peduncle in some Robo 2 mutants ( $n=3$ of 4 brains) (data not shown).

Previous studies have shown that Slit2 is required for the guidance of corticocortical projections at the corpus callosum (Bagri et al., 2002; Shu et al., 2003). However, analysis of Slit2-AP binding assays revealed only minor defects in the development of the corpus callosum in Robo1 mutant embryos, and no apparent abnormalities in Robo2 mutant embryos compared with controls $(n=3)$ (Fig. $2 E, F)$. Immunohistochemistry against $\mathrm{NPY}(n=4)$ (Fig. $4 M-O)$ or DiI tracing from the neocortex $(n=4)$ (Fig. $5 M-O)$ reinforced this view, because both methods failed to reveal major defects in the development of callosal projections in Robo1 or Robo2 single mutants.

\section{Corticofugal axon guidance is severely disrupted in Robo1; Robo 2 double mutants}

The mild defects seen in the single mutants suggested two possibilities: (1) Robo receptors do not mediate the function of Slit proteins during the development of forebrain connections, or (2) Robol and Robo 2 receptors are mostly coexpressed and function 

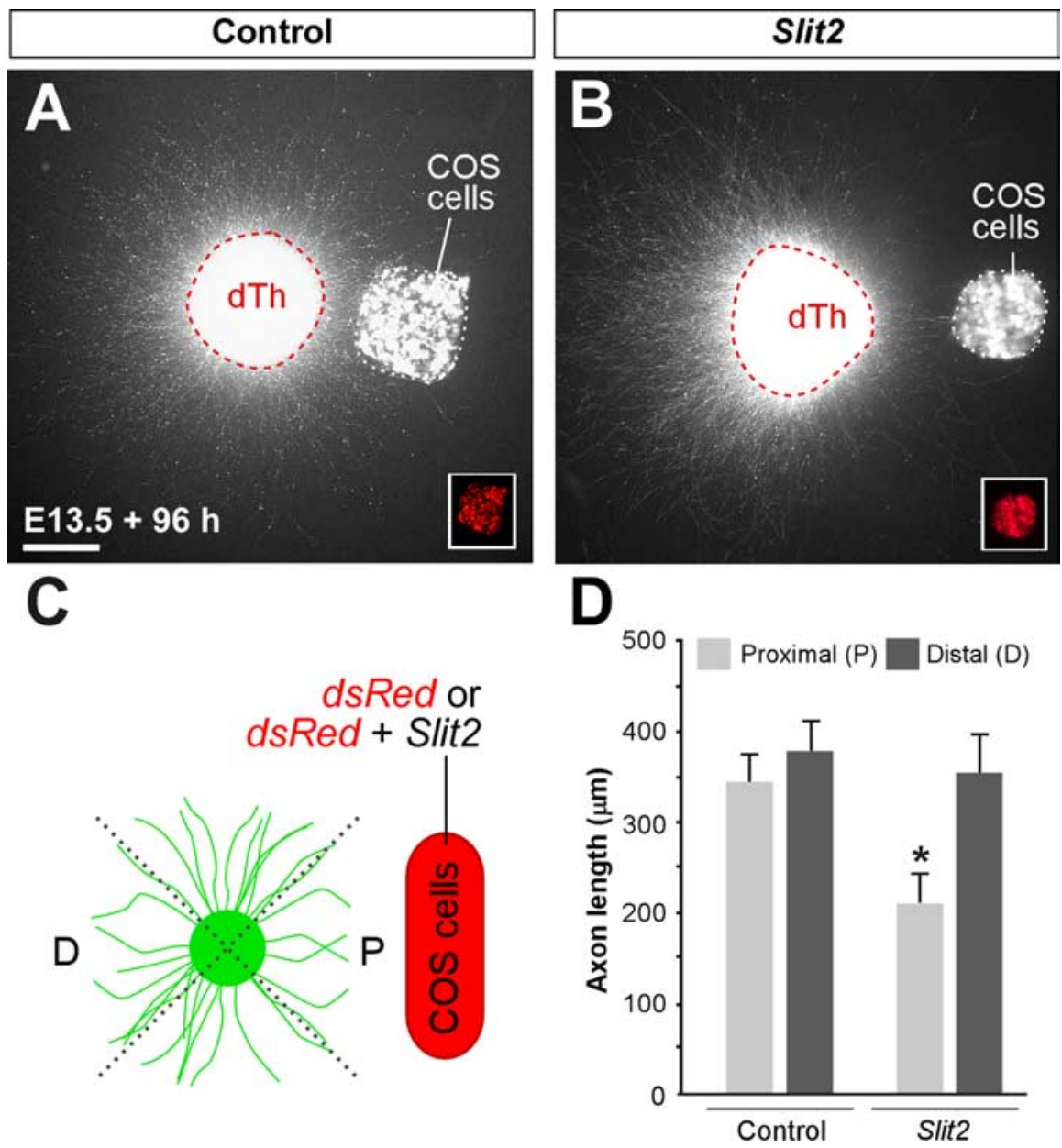

Figure 3. Dorsal thalamic explants from E13.5 GFP transgenic mice showing Slit2 repulsion to dorsal thalamic axons. $\boldsymbol{A}, \boldsymbol{B}$, Dorsal thalamic explants were cocultured in collagen for $4 \mathrm{~d}$ in vitro either with mock-transfected COS cells $(\boldsymbol{A})$ or Slit2-transfected COS cells $(\boldsymbol{B})$. C, Scoring scheme used to test the effect of Slit2 on dorsal thalamus (dTh) axons in the experiments presented in $\boldsymbol{A}$ and $\boldsymbol{B}$. Explants were subdivided into four equal sectors. The two sectors used for quantification were designated as proximal $(P)$ and distal (D) in relation to the COS cell aggregate. The length of the 13 longest axons in each sector was measured in every explant. $\boldsymbol{D}$, Quantification of the axonal growth of dTh explants cultured in collagen with mock-transfected COS cells $(n=19)$ or Slit2transfected $\operatorname{COS}$ cells $(n=22)$ show a repulsive activity of Slit2. Mean length of axons was as follows: proximal, $345.8 \pm 32.3 \mu \mathrm{m}$; distal, $374.9 \pm 33.0 \mu \mathrm{m}$ (average \pm SEM) in controls; and proximal, $210.4 \pm 29.4 \mu \mathrm{m}$; distal, $356.1 \pm 43.5 \mu \mathrm{m}$ (average \pm SEM) in experimental cases. Significant differences were observed among proximal sectors in the case of Slit2 compared with controls cases. ${ }^{*} p>0.001$. Scale bar, $200 \mu \mathrm{m}$.

cooperatively in corticofugal and thalamocortical axons. In the latter case, each Robo receptor may functionally compensate for the loss of the other one, providing a rational explanation to the absence of guidance defects found in either Robol or the relatively minor abnormalities present in Robo 2 single mutants. To test this hypothesis, we next examined the organization of cortical and thalamic projections in Robo1;Robo2 double mutants.

In contrast to Robo1 and Robo 2 single mutants, a simple cytoarchitectonical analysis of the telencephalon of Robo1;Robo2 double mutants revealed the existence of large bundles of ectopic fibers crossing the ventral midline at E18.5 $(n=5)$ (Fig. $6 A-C)$. This abnormal crossing of fiber tracts at the level of the anterior commissure was also observed on sections stained with antibodies against L1 $(n=5)$ (Fig. $6 D-F)$. L1 and calbindin immunostaining on sagittal sections revealed even more clearly that, in addition to the anterior commissure, large bundles of axons aberrantly cross the midline in the basal telencephalon of Robo1; Robo2 double mutants $(n=3)$ (Fig. $6 G-L)$. Because of the presence of the ectopic commissural axons, the anterior commissure is always displaced dorsally in Robo1; Robo2 double mutants (Fig. $6 K, L$ ).

To determine the source of the ectopic commissural axons found in the basal telencephalon of Robo1;Robo2 double mutants, we next traced the trajectory of cortical axons by placing crystals of DiI in the developing neocortex. At E18.5, DiI injections in the parietal cortex of wild-type mice revealed a thick bundle of labeled axons coursing through the internal capsule as they progress toward the diencephalon $(n=10)$ (Fig. $7 A, B)$. In contrast, DiI placements in the neocortex of Robo1;Robo2 double mutants showed that most corticofugal axons were diverted toward the midline, which they abnormally crossed $(n=8)$ (Fig. $7 C, D, F)$. Interestingly, many cortical axons appear to return toward the midline after crossing it (Fig. $7 D, F$ ), because only a few axons were found to grow away from the midline toward the contralateral cortex (data not shown). DiI injections in the neocortex, in particular its caudal part, labeled some axons that did not decussate in the ventral telencephalon but followed their normal route toward the diencephalon (Fig. 7E) (data not shown). The abnormal trajectory of corticofugal axons was observed in embryos as early as E14.5 $(n=3)$ (supplemental Fig. 2, available at www.jneurosci.org as supplemental material).

The massive number of axons that abnormally cross the ventral telencephalon in Robo1;Robo2 double mutants suggests that both corticothalamic (layer 6) and cerebral peduncle (layer 5) projections are affected in the absence of Robo function. Accordingly, immunohistochemistry for NPY as well as DiI tracing experiments from the parietal cortex revealed that only a few cortical axons reach the dorsal thalamus in Robo1;Robo2 double mutants $(n=8)$ (Fig. $8 A-D, G, H)$. Moreover, these axons follow a more ventral trajectory than wild-type axons as they enter the diencephalon on their way to the dorsal thalamus (Fig. $8 A, B, G, H$ ).

Whereas some corticothalamic axons were consistently found in the absence of Robol and Robo2 function, DiI placements in the neocortex revealed that virtually no corticospinal axons reach the diencephalon through the cerebral peduncle in Robo1;Robo2 double mutants $(n=8)$ (Fig. $8 E-H)$. Thus, Robo1 and Robo2 appear essential for the normal development of layer 5 cortical projections.

\section{Simultaneous loss of Robo1 and Robo2 perturbs} corticocortical projections at the corpus callosum We next analyzed whether the projections of corticocortical axons were also impaired in the absence of both receptors. At E18.5, Nissl staining revealed that the size of the corpus callosum was reduced in Robo1;Robo2 double mutants compared with wildtype mice $(n=5)$ (Fig. $9 A, B)$. In addition, two large ectopic bundles of fibers were also found on either side of the corpus 
callosum of Robo1;Robo2 double mutants, which resemble Probst bundles (Fig. 9B). These ectopic bundles were also observed when sections were stained for NPY $(n=$ 3) (Fig. 9D). Moreover, DiI tracing experiments demonstrated that the ectopic axons were corticocortical axons that abnormally defasciculated from the corpus callosum and coursed ventrally into the septum $(n=4)$ (Fig. $9 E-H)$. This defect was consistently observed after DiI placements in different cortical regions (data not shown).

\section{Prominent thalamocortical axon guidance defects in Robo1;Robo2 double mutants}

We next investigated the consequences of the simultaneous loss of Robol and Robo2 receptors in the guidance of thalamocortical axons. At E18.5, immunohistochemistry against calretinin, which labels thalamocortical projections originating from medial thalamic nuclei, revealed that numerous thalamic axons abnormally invade the hypothalamus, failing to turn rostrally into the telencephalon $(n=3)$ (Fig. $10 A-C, M, N$ ). In agreement with this observation, DiI injections into the dorsal thalamus of E18.5 Robo1;Robo2 double mutants showed that, compared with control mice, the vast majority of thalamocortical projections fail to enter the telencephalon and instead invade the hypothalamus $(n=3)$ (Fig. $10 G-I, M, N)$, a phenotype that was observed already in E14.5 embryos $(n=3)$ (supplemental Fig. 2 , available at www.jneurosci.org as supplemental material).

DiI injections in the dorsal thalamus revealed that only some thalamic axons enter the telencephalon in Robo1;Robo2 double mutants. Once in the telencephalon, very few thalamocortical axons were found to grow through the internal capsule into the cerebral cortex $(n=5)$ (Fig. $10 J-L, M, N)$. Instead, many of the thalamocortical fibers that succeeded in entering the telencephalon were abnormally diverted toward the midline, which they cross (Fig. $10 D-F, M, N$ ) (data not shown). In summary, thalamocortical projections are severely disrupted in the absence of Robol and Robo2 function, with many axons aberrantly projecting toward the hypothalamus or the telencephalic ventral midline.

\section{Discussion}

The functioning of the cerebral cortex relies on several stereotypical long-distance projections, such as the corticofugal, callosal, and thalamocortical connections.
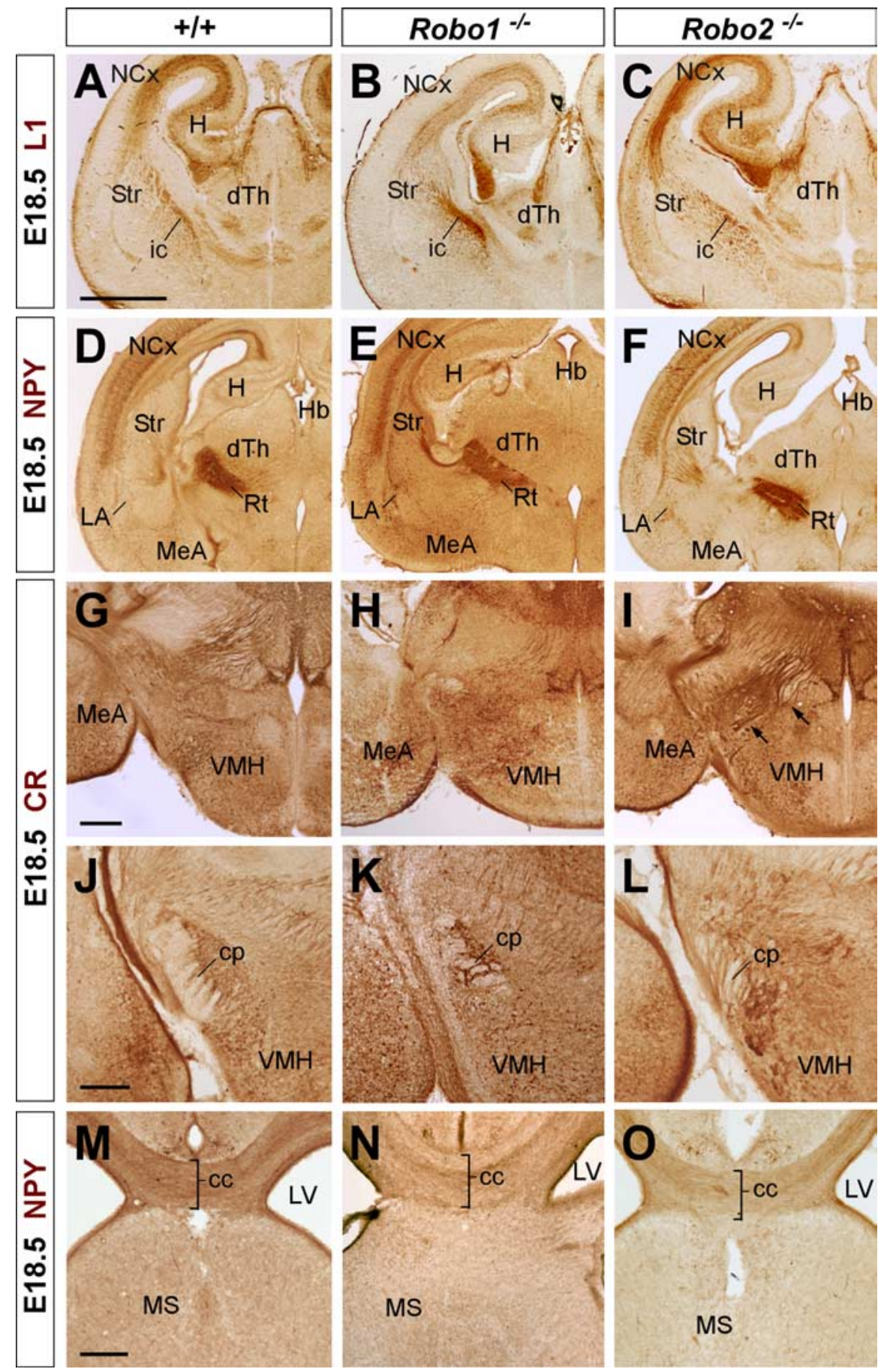

Figure 4. Abnormal axonal trajectories in the forebrain of Robo1 and Robo2 single-mutant mice. Coronal sections through the telencephalon of E18.5 embryos showing cell adhesion molecule L1 (L1) $(\boldsymbol{A}-\boldsymbol{C})$, NPY $(\boldsymbol{D}-\boldsymbol{F}, \boldsymbol{M}-\mathbf{0})$, and calretinin (CR) $(\mathbf{G}-\boldsymbol{I})$ immunohistochemistry in wild-type $(\boldsymbol{A}, \boldsymbol{D}, \boldsymbol{G}, \boldsymbol{J}, \boldsymbol{M}), \operatorname{Robo1}(\boldsymbol{B}, \boldsymbol{E}, \boldsymbol{H}, \boldsymbol{K}, \boldsymbol{N})$, and $\operatorname{Roboz}(\boldsymbol{C}, \boldsymbol{F}, \boldsymbol{I}, \boldsymbol{L}, \mathbf{O})$ mutant mice. $A-C$, In wild-type embryos, L1 + axons are confined to the intermediate zone of the neocortex (NCX), striatum (Str), and dorsal thalamus (dTh). In Robo1 and Robo2 mutants, $\mathrm{L} 1+$ fascicles are observed at the NCx and Str in a similar pattern as in wild-type embryos. D-F, Immunohistochemistry for NPY demonstrates that corticothalamic axons reach the diencephalon in wild-type $(\boldsymbol{D})$, and Robo1 (E) and Robo2 mutant $(\boldsymbol{F})$ brains. $\mathbf{G}-\mathbf{I}$, Coronal sections at the level of the diencephalon showing the trajectory of thalamocortical axons by immunohistochemistry for calretinin $(C R)$ in wild-type $(\boldsymbol{G})$, and Robo1 $(\boldsymbol{H})$ and Robo2 (I) mutant brains. At this level, $C R+$ thalamocortical axons normally turn rostrally to enter the telencephalon, thus leaving the plane of section as observed in wild-type $(\boldsymbol{G})$ and Robo1 mutants $(\boldsymbol{H})$. In contrast, abnormal $\mathrm{CR}+$ bundles were observed descending to the hypothalamus in Robo2 mutants ( $\boldsymbol{I}$, arrows). $J-\boldsymbol{L}$, Abnormal development of the cerebral peduncle (cp) in Robo2 mutant brains ( $\boldsymbol{L}$ ), as revealed by calretinin immunostaining. $\mathbf{M}-\mathbf{0}$, Coronal sections at the level of the corpus callosum (cc) showing corticocortical fibers labeled by NPY immunohistochemistry in wild-type $(\boldsymbol{M})$, and Robol $(\boldsymbol{N})$ and Robo2 (0) mutant mice. ic, Internal capsule; H, hippocampus; $\mathrm{Hb}$, habenula; Rt, reticular thalamic nucleus; VMH, ventromedial hypothalamic nucleus; MeA, medial amygdala; LA, lateral amygdala; MS, medial septum; LV, lateral ventricle. Scale bars: $\mathbf{A}-\boldsymbol{F}, 1 \mathrm{~mm} ; \mathbf{G}-\mathbf{L}, 100 \mu \mathrm{m} ; \boldsymbol{M}-\mathbf{0}, 200 \mu \mathrm{m}$. 


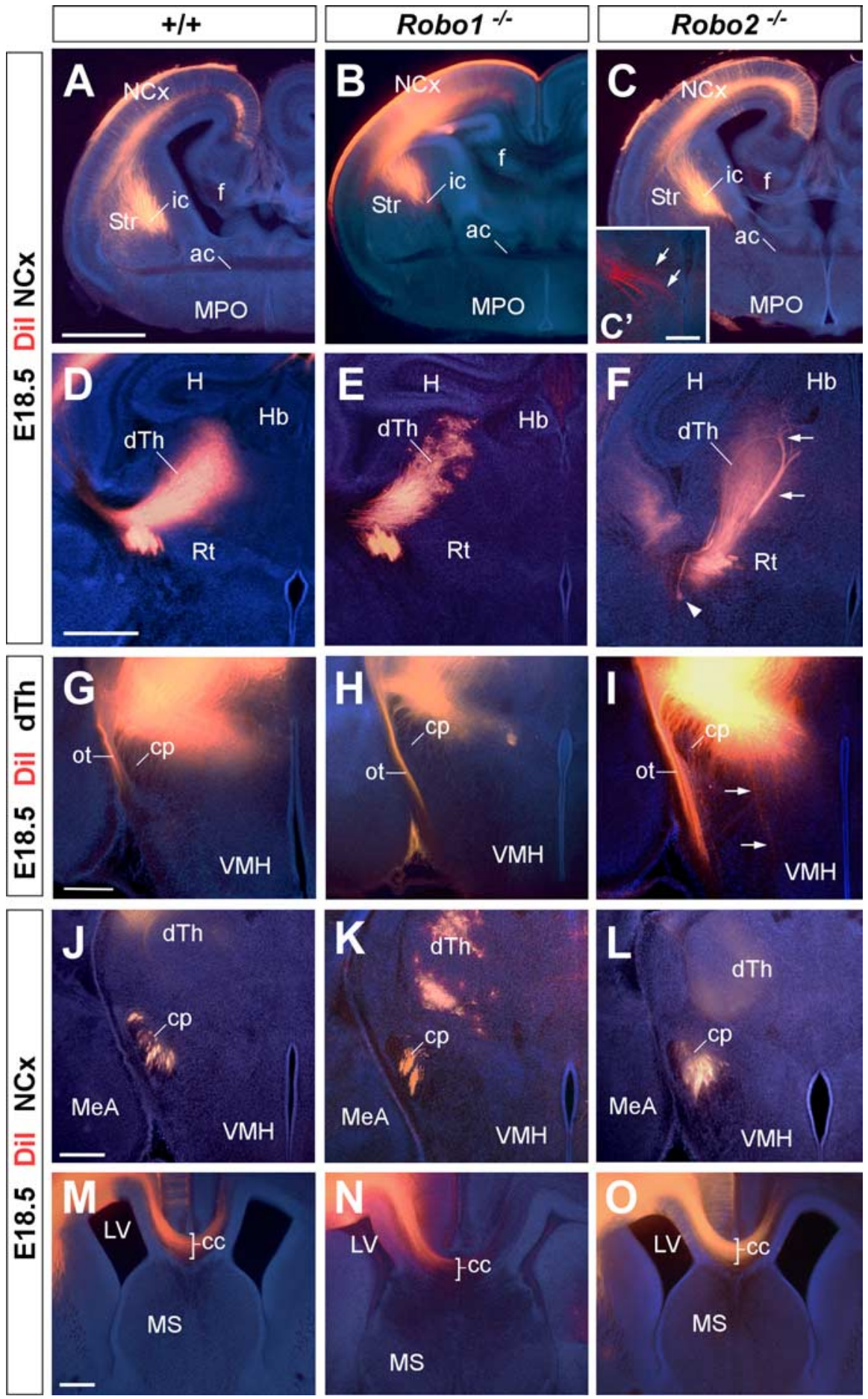

Figure 5. Axon guidance defects in the forebrain of Robo2 single-mutant mice. Coronal sections through the telencephalon of E18.5 brains with Dil implanted in the neocortex $(\mathrm{NCx})(\boldsymbol{A}-\boldsymbol{F}, \boldsymbol{J}-\mathbf{0})$ or in the dorsal thalamus (dTh) $(\boldsymbol{G}-\boldsymbol{I})$ of wild-type $(\boldsymbol{A}, \boldsymbol{D}, \boldsymbol{G}, \boldsymbol{J}$ $\boldsymbol{M})$, and $\operatorname{Robo1}(\boldsymbol{B}, \boldsymbol{E}, \boldsymbol{H}, \boldsymbol{K}, \boldsymbol{N})$ and $\operatorname{Robo2}(\boldsymbol{C}, \boldsymbol{F}, \boldsymbol{I}, \boldsymbol{L}, \mathbf{0})$ mutant mice, showing computer-generated overlays of Dil-labeled axons and Hoechst counterstain. $\boldsymbol{A}-\boldsymbol{C}^{\prime}$, Coronal sections showing labeled Dil axons extending from the cortex into the internal capsule (ic) in wild-type $(\boldsymbol{A})$, and Robo1 (B) and Robo2 (C, $\left.\boldsymbol{C}^{\prime}\right)$ mutant mice. $\boldsymbol{D}-\boldsymbol{F}$, Abnormal defasciculation (arrowhead) and targeting (arrows) of corticothalamic axons at the dorsal thalamus of Robo2 mutant mice $(\boldsymbol{F})$. In Robo 1 mutant mice, labeled axons extend from the cortex into the dorsal thalamus normally. $\mathbf{G}-\mathbf{I}$, Coronal sections through the caudal diencephalon showing dorsal thalamic fibers abnormally entering the hypothalamus in Robo2 mutant mice $(\boldsymbol{I})$. No guidance defects were observed in the thalamocortical axons in Robo1 mutant mice $(\boldsymbol{H})$ compared with wild type $(\boldsymbol{G})$. J-L, Coronal sections showing corticospinal labeled axons at the cerebral peduncle (cp) of wild-type $(\boldsymbol{J})$, and $R_{0 b 01}(\boldsymbol{K})$ and $\operatorname{Rob02}(\boldsymbol{L})$ mutant mice. Note the abnormal ventral position of the cerebral peduncle and the defasciculation of axons in Robo2 mutant mice. $\boldsymbol{M - 0}$, Rostral coronal sections showing corticocortical axons at the corpus callosum (cc) of wild-type $(\boldsymbol{M})$, and Robo1 (N) and Robo2 (0) mutant mice. No guidance defects were observed in either of the Robo single mutants. ac, Anterior commissure; Str, striatum; f, fimbria; MPO, medial preoptic area; $H$, hippocampus; Rt, reticular thalamic nucleus; $\mathrm{Hb}$, habenula; $\mathrm{VMH}$, ventromedial hypothalamic nucleus; MeA, medial amygdala nucleus; MS, medial septum; ot, optic tract; LV, lateral ventricle. Scale bars: $\boldsymbol{A}-\mathbf{C}, 1 \mathrm{~mm} ; \boldsymbol{C}^{\prime}, 200 \mu \mathrm{m} ; \mathbf{D}-\boldsymbol{F}, 500 \mu \mathrm{m} ; \mathbf{G}-\mathbf{0}, 300 \mu \mathrm{m}$.
Several studies have examined the early development of these projections and have identified pioneering axonal populations as well as potential intermediate targets and choice points for these axons (McConnell et al., 1989; De Carlos and O'Leary, 1992; Métin and Godement, 1996; Molnár et al., 1998; Braisted et al., 1999; Tuttle et al., 1999; Auladell et al., 2000; López-Bendito et al., 2006). In addition, multiple molecules that participate in the guidance of these connections have been identified, providing a comprehensive frame in which to understand their development (Serafini et al., 1996; Métin et al., 1997; Richards et al., 1997; Braisted et al., 2000; Leighton et al., 2001; Bagri et al., 2002; López-Bendito et al., 2006). Thus, Slits play a fundamental role in the development of corticocortical callosal projections, layer 5 corticofugal projections toward the mesencephalon, pons, and spinal cord, and layer 6 corticothalamic projections (Bagri et al., 2002; Shu et al., 2003). Moreover, the development of the reciprocal thalamocortical projections also depends on Slit function (Bagri et al., 2002). Here, we demonstrate that the function of Slits in the guidance of these connections is mostly mediated by the coordinated activity of Robo1 and Robo2 receptors.

\section{Robo1 and Robo2 have mostly redundant functions in forebrain axon guidance}

Our previous analysis of Slit1 and Slit2 mutants led us to suggest that Slit proteins contribute in at least three different ways to the development of the mammalian forebrain: (1) the maintenance of the dorsoventral position of longitudinal axonal tracts by preventing axons from entering into ventral regions; (2) the prevention of axonal extension toward and across the midline; and (3) the channeling of axons into particular regions, such as commissures (Bagri et al., 2002). Slit1 and Slit2, which are expressed in partially overlapping patterns in the forebrain, cooperate to fulfill these functions: Slit2 is mostly responsible of preventing ventral invasion and axon channeling (1 and 3), whereas both Slit1 and Slit2 contribute to prevent midline crossing of ipsilateral tracts (2) (Fig. 11).

The finding that Robol and Robo2 proteins are expressed in developing forebrain axons at the time when these connections are formed, led us to hypothesize that these receptors may play an important role in their guidance. However, analysis of mouse mutants for Robo1 or Robo2 
revealed very few guidance errors in the absence of either one of these receptors. In the case of Robo 2 mutants, our analysis revealed only relatively moderate defects in the dorsoventral position of corticofugal, corticothalamic, and thalamocortical tracts, which enter ventral regions that they normally avoid (Fig. 11). In the case of Robol mutants, we could detect only very minor defects in the development of some corticocortical callosal connections (Fig. 2E). In contrast to our findings, a recent analysis of a different mutant allele of Robol showed a more severe phenotype, demonstrating that the function of this receptor is essential for the development of callosal projections, the absence of which cannot be compensated by the function of Robo2 (Andrews et al., 2006). We do not know the source of the discrepancy; however, it is possible that, as previously observed with other genes (Zheng et al., 2003), differences in the genetic background of the two mutant strains could explain the different penetrance of the Robol mutation. In addition, our Robol allele is likely to be a severe hypomorph rather than a complete null (Long et al., 2004); this would be consistent with the observation of weak Slit1-AP binding in Robo1;Robo2 double mutants (Fig. 2G). In any case, our Robol allele only appears to behave as a hypomorph in the callosal projection [compared with the Robol allele described by Andrews et al. (2006)], because the remaining defects observed in Robo1;Robo2 double mice phenocopy those found in Slit1;Slit2 double mutants.

The absence of severe axon guidance defects in Robo1 and Robo 2 single mutants suggests that both receptors cooperate in the guidance of most forebrain projections. However, as described above for the callosal projections in Robol mutants (this study; Andrews et al., 2006), there are defects in Robo 2 mutants that cannot be compensated by Robol function, such as the ventrally projecting axons found in corticofugal and thalamocortical tracts. This suggests that that Robol and Robo2 functions may not be completely redundant. Interestingly, cortical and thalamic projections also overshoot ventrally in Slit2, but not in Slit1 mutants, which led to the proposal that the range of Slit2 function includes regions more distant from the midline than Slit1 (Fig. 11) (Bagri et al., 2002). Why do axons overshoot ventrally in Robo2 mutants? One possibility is that some cortical and thalamic neurons do not express significant levels of Robol receptors. This is unlikely, however, because in the absence of both receptors axons abnormally cross the midline, and Robo2 mutants do not have obvious midline crossing defects. Alternatively, Slit2 binding to Robo2 may be more effective than it is to Robol, which therefore may not be able to mediate the repulsion required to maintain growing axons at their normal dorsoventral position (Fig. 11). Consistent with this
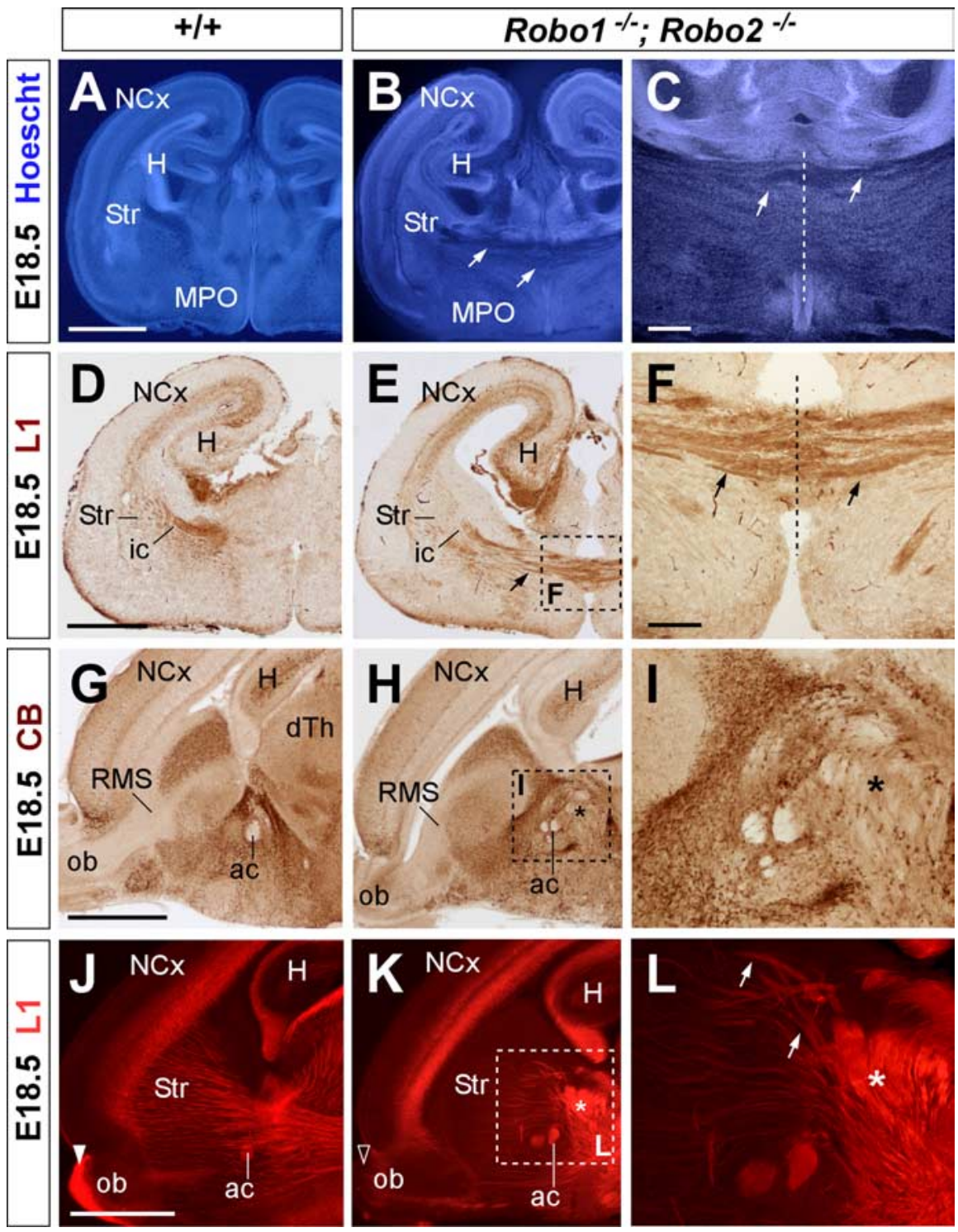

Figure 6. Abnormal axonal trajectories in the forebrain of Robo1;Robo2 double-mutant mice. Coronal $(\boldsymbol{A}-\boldsymbol{F})$ and sagittal $(\mathbf{G}-\boldsymbol{L})$ sections through the telencephalon of E18.5 embryos showing Hoechst staining $(\boldsymbol{A}-\boldsymbol{C})$, cell adhesion molecule $L 1(D-F, J-L)$, and calbindin $(\boldsymbol{G}-\boldsymbol{I})$ immunohistochemistry in wild-type $(\boldsymbol{A}, \boldsymbol{D}, \boldsymbol{G}, \boldsymbol{J})$ and Robo1;Robo2 $(\boldsymbol{B}, \boldsymbol{C}, \boldsymbol{E}, \boldsymbol{F}, \boldsymbol{H}, \boldsymbol{I}, \boldsymbol{K}, \boldsymbol{L})$ mutant mice. $\boldsymbol{A}-\boldsymbol{C}$, Hoechst the midline in Robo1;Robo2 mutants ( $\boldsymbol{E}, \boldsymbol{F}$, arrows). $\mathbf{G}-\boldsymbol{I}$, Immunohistochemistry for calbindin delineates the abnormal crossing of few thalamic L1 + axons extend through the striatum in Robo 1; Robo2 mutants because they accumulate in the midline (asterisk). The midline is indicated by a dotted line in $C$ and $F$. NCX, Neocortex; ic, internal capsule; ob, olfactory bulb, RMS, rostral migratory steam; Str, striatum; H, hippocampus. Scale bars: $\boldsymbol{A}, \boldsymbol{B}, \boldsymbol{D}, \boldsymbol{E}, \boldsymbol{G}, \boldsymbol{H}, \boldsymbol{J}, \boldsymbol{K}, 1 \mathrm{~mm} ; \boldsymbol{C}, 300 \mu \mathrm{m} ; \boldsymbol{F}, \boldsymbol{I}, \boldsymbol{L}, 200 \mu \mathrm{m}$.

possibility, full-length Slit2 or its proteolytic N-terminal fragment bind more effectively to Robo2 than to Robol in vitro (Nguyen BaCharvet et al., 2001). Thus, it is conceivable that the interaction between Slit 2 and Robo 2 constitutes the primary signaling system involved in maintaining the dorsoventral position of corticofugal and thalamocortical projections.

Similar forebrain guidance defects in Robo1;Robo2 and Slit1; Slit2 double mutants

The lack of prominent forebrain axon guidance defects in Robol and Robo 2 mutants suggests that both receptors are indeed expressed by the same neurons and thereby may primarily compen- 


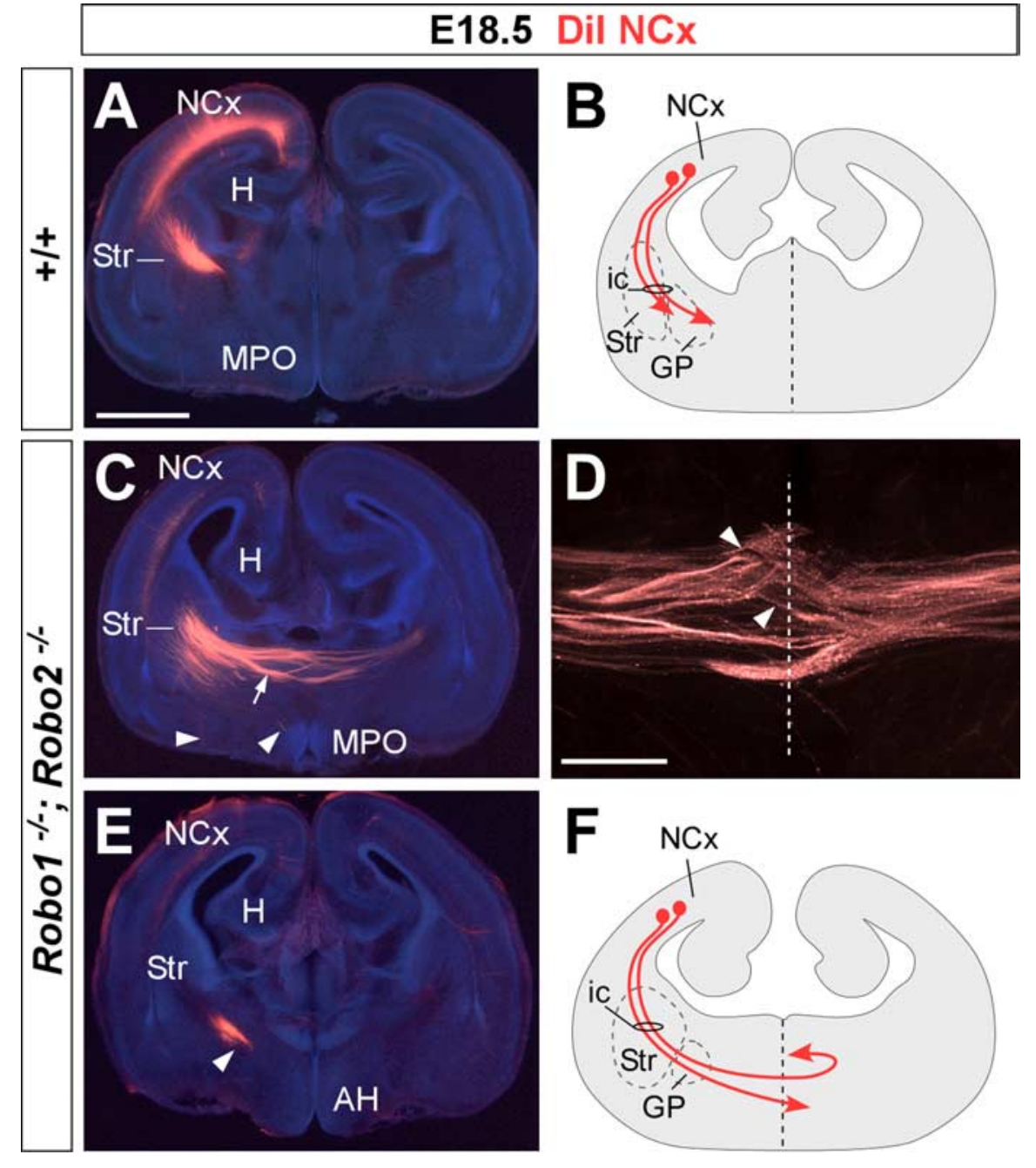

Figure 7. Corticofugal axons abnormally reach the telencephalic midline in Robo1;Robo2 double-mutant mice. Coronal sections through the telencephalon of E18.5 brains with Dil implanted in the neocortex (NCX), showing computer-generated overlays of Dil-labeled corticofugal axons and Hoechst counterstaining from wild-type $(\boldsymbol{A})$ and Robo 1;Robo2 mutants $(\boldsymbol{C}-\boldsymbol{E})$. The midline is indicated with a dotted line in $\boldsymbol{D}$. The schemas summarize the results obtained in control $(\boldsymbol{B})$ and Robo1; Robo2 mutants $(\boldsymbol{F}) . \boldsymbol{A}, \boldsymbol{B}$, In wild-type mice, labeled axons extend from the cortex into the striatum (Str). C-F, In Robo 1; Robo2 mutants, labeled axons from the internal capsule (ic) abnormally approach the midline and cross it ( $\boldsymbol{C}$, arrow). A few axons that reach the midline course ventrally (arrowheads). Most of the axons that crossed the midline at more anterior levels were found in the contralateral side, where they either travel to the base of the telencephalon or extend toward the contralateral cortex $(\boldsymbol{C}, \boldsymbol{D})$. MP0, Medial preoptic area; $H$, hippocampus, $A H$, anterior hypothalamus. Scale bars: $A, C, E, 1 \mathrm{~mm} ; \boldsymbol{D}, 300 \mu \mathrm{m}$.

sate each other's function in the absence of one of the receptors. This compensation does not appear to be at the level of gene expression or protein localization, because Robol protein or mRNA levels do not change in the forebrain of Robo2 mutant mice, and, conversely, Robo 2 protein or mRNA levels do not vary in Robo1 mutants (supplemental Figs. 3, 4, available at www. jneurosci.org as supplemental material). Instead, it seems most likely that cortical and thalamic neurons normally contain functional levels of both receptors in growing axons. This hypothesis is agreement with the analysis of Robo1;Robo2 double mutants, which mostly recapitulate the phenotypes observed in Slit1;Slit2 double mutants (Bagri et al., 2002) (Fig. 11).

In Slit1;Slit2 double mutants, most corticofugal and corticothalamic axons fail to reach the diencephalon, because they massively cross the midline in the ventral telencephalon (Bagri et al., 2002). Thalamocortical axons also make prominent guidance errors in Slit1;Slit2 double mutants; many run into the hypothalamic region, and the few that enter the telencephalon also turn aberrantly toward the midline. Thus, in the simultaneous absence of Slit1 and Slit2 or Robo1 and Robo2, cortical and thalamic ipsilateral projections fail to maintain their ipsilateral condition and instead abnormally invade the midline. Because these prominent defects are not present in either Robo1 or Robo2 single mutants (this study; Andrews et al., 2006), it seems clear that Slit1 and Slit2 prevent midline crossing of ipsilateral projections in the mammalian forebrain through both Robol and Robo 2 receptors.

In the spinal cord, commissural axons upregulate Robol and Robo2 once they have crossed the midline, thereby contributing to their navigation beyond the floor plate (Long et al., 2004). In contrast, the only population of commissural axons examined in this study, the corticocortical callosal axons, is sensitive to Slit proteins before midline crossing. In this region, two glial populations adjacent to the midline, the glial wedge and the indusium griseum, express Slit2 and form a narrow pathway through which callosal axons extend (Shu et al., 2003). It has been recently suggested that Robol might be the unique mediator of Slit2 function in the formation of the corpus callosum (Andrews et al., 2006). Our results, however, strongly suggest that Robo 2 also contributes to the formation of this commissure, because we observed very prominent defects in Robol; Robo2 double mutants but no abnormalities in either Robo1 or Robo2 single mutants. Even assuming that the Robol allele analyzed here is only a severe hypomorph, our genetic analysis strongly suggests that Robo2 signaling contributes along with Robol in the formation of the corpus callosum.

\section{Interaction of Slit/Robo signaling with other molecules}

It has been previously shown that molecules such as cell surface heparan sulfates may modulate the interaction of Slits and Robo receptors. Thus, biochemical experiments have shown that Slits bind the heparan sulfate proteoglycan glypican-1 (Liang et al., 1999; Ronca et al., 2001). Heparan sulfate enhances the affinity of Slit2 for Robo1 receptors in vitro, and removal of cell surface heparan sulfate by heparinase III treatment or addition of saturating amounts of heparan sulfate abolishes the repulsive activity of Slit2 toward olfactory bulb axons in explant cultures $(\mathrm{Hu}$, 2001). Moreover, nervous system-specific conditional mutants for EXT1, a glycosyltransferase enzyme required for the synthesis of heparan sulfate, display guidance defects at the optic chiasm that are similar to those found in Slit1;Slit2 double mutants (Plump et al., 2002; Inatani et al., 2003). Furthermore, reduction of one Ext1 allele in Slit $2^{-/-}$mice, which otherwise have a relatively normal optic chiasm, cause profound retinal axon misguidance similar to those found in conditional Ext1 mutants and Slit1;Slit2 double mutants. Similarly, zebrafish mutants for both 

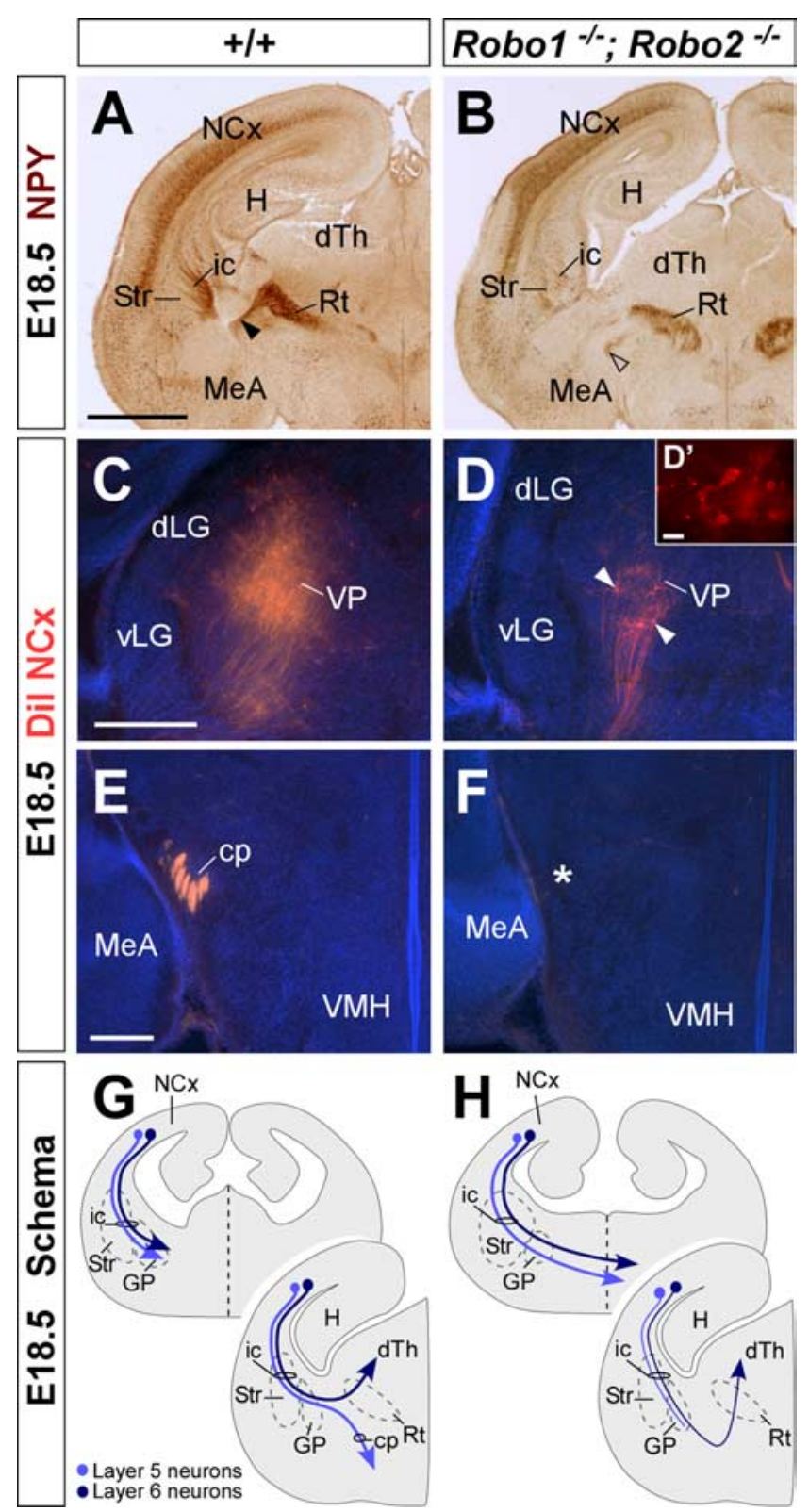

Figure 8. Corticothalamic and corticospinal projections are severely defective in Robo1; Robo2 double-mutant mice. $\boldsymbol{A}, \boldsymbol{B}$, Coronal sections through the telencephalon of E18.5 brains showing NPY immunohistochemistry in wild-type $(\boldsymbol{A})$ and Robo1; Robo2 (B) mutant mice. NPY immunohistochemistry demonstrates that some cortical axons reach the dorsal thalamus (dTh) in Robo 1; Robo2 mutants, although through an abnormally ventral path (open arrowhead). C, D, Coronal sections through the dTh of E18.5 embryos with Dil implanted in the neocortex (NCx), showing computer-generated overlays of Dil retrogradely labeled cells and Hoechst counterstain from wild-type $(\boldsymbol{C})$ and Robo1;Robo2 mutants $(\boldsymbol{D})$. The number of retrogradely labeled cells found in the dTh is greatly reduced in Robo1;Robo2 mutants ( $\boldsymbol{D}$, arrowheads). $\boldsymbol{E}, \boldsymbol{F}$, The cerebral peduncle ( $(\boldsymbol{p})$ is absent in Robo1;Robo2 mutants $(\boldsymbol{F})$, as revealed by the lack of Dillabeled corticospinal fibers in the structure. The majority of these fibers cross abnormally the midline at more rostral levels. $\boldsymbol{G}, \boldsymbol{H}$, The schemas summarize the pathway followed by corticothalamic (layer 6; dark blue) and corticospinal (layer 5; light blue) axons in wild-type (G), and Robo1;Robo2 (H) mutant mice. Str, Striatum; Rt, reticular thalamic nucleus; VMH, ventromedial hypothalamic nucleus; MeA, medial amygdala; VP, ventroposterior nucleus; dLG, dorsal lateral geniculate nucleus, vLG, ventrolateral geniculate nucleus; ic, internal capsule; GP, globus pallidus; $\boldsymbol{H}$, hippocampus. Scale bars: $\boldsymbol{A}, \boldsymbol{B}, 1 \mathrm{~mm} ; \boldsymbol{C}, \boldsymbol{D}, 300 \mu \mathrm{m} ; \boldsymbol{D}^{\prime}, 10 \mu \mathrm{m} ; \boldsymbol{E}, \boldsymbol{F}, 200 \mu \mathrm{m}$.

ext2 (dackel, dak) and extl3 (boxer, box), two additional glycosyltransferases implicated in heparan sulfate biosynthesis, show retinal axon guidance defects that phenocopy robo 2 mutants (Hutson and Chien, 2002; Lee et al., 2004). Together, these results

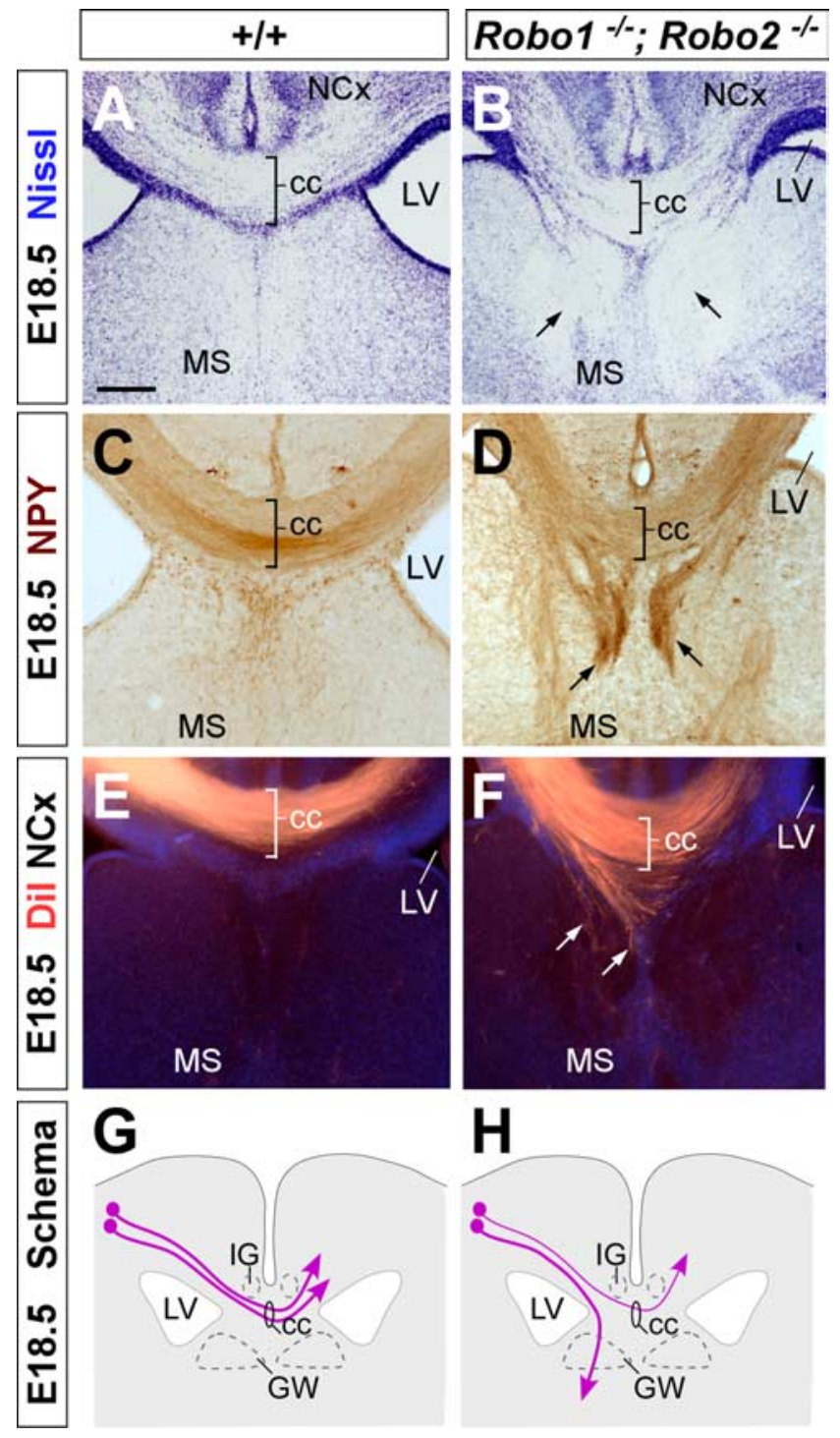

Figure 9. Abnormal development of the corpus callosum in Robo1;Robo2 double-mutant mice. Coronal sections through the telencephalon of E18.5 fetuses showing NissI stain $(\boldsymbol{A}, \boldsymbol{B})$ and $\operatorname{NPY}(\boldsymbol{C}, \boldsymbol{D})$ immunohistochemistry in wild-type $(\boldsymbol{A}, \boldsymbol{C})$ and Robo 1; Robo2 double-mutant mice ( $\boldsymbol{B}$, D) mutant mice. $\boldsymbol{A}-\boldsymbol{D}$, Nissl staining and NPY immunohistochemistry demonstrates that Robo1; Robo2 double-mutant mice have a small corpus callosum (cc) and that large ectopic bundles of axons form on either side of it ( $\boldsymbol{B}, \boldsymbol{D}$, arrows). $\boldsymbol{E}, \boldsymbol{F}$, Coronal sections through the telencephalon of E18.5 fetuses with Dil implanted in the neocortex (NCX), showing Dil-labeled corticocortical axons extending through the corpus callosum in wild-type $(\boldsymbol{E})$ and Robo1; Robo2 double-mutant $(\boldsymbol{F})$ mice. Note that many axons are abnormally directed ventrally before they reach the midline ( $\boldsymbol{F}$, arrows). $\boldsymbol{G}, \boldsymbol{H}$, The schemas summarize the pathways followed by corticocortical axons through the corpus callosum in wild-type $(\boldsymbol{G})$ and Robo1;Robo2 double-mutant $(\boldsymbol{H})$ mice. MS, Medial septum; LV, lateral ventricle; GW, glial wedge; IG, indusium griseum. Scale bars: $\boldsymbol{A}-\boldsymbol{F}$, $200 \mu \mathrm{m}$.

suggest that heparan sulfate plays a physiologically essential role in Slit/Robo-mediated retinal axon guidance at the optic chiasm.

Although heparan sulfate may function in the extracellular environment, some evidence suggests that it may also or instead function on the surface of Robo-expressing, Slit responding cells, where it may contribute to concentrate Slit protein and promote its binding to Robo receptors. In the telencephalon, thalamic neurons express the heparan sulfate proteoglycan $\mathrm{N}$-syndecan (Kinnunen et al., 1999), and both corticofugal and thalamocortical axons are labeled with antibodies against heparan sulfate (J. A. Sánchez and O. Marín, unpublished observations). Thus, it 


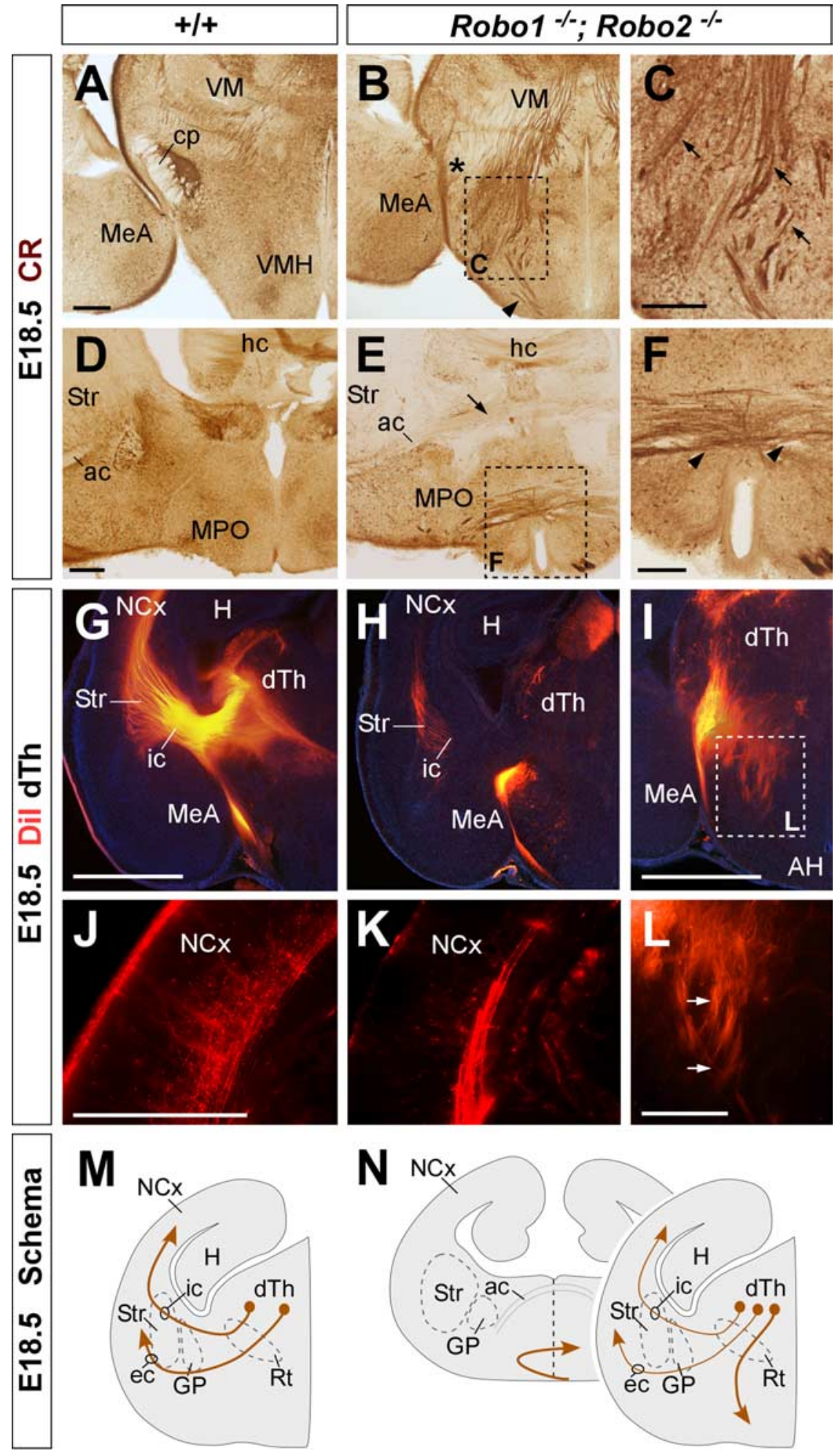

Figure 10. Thalamocortical axons follow abnormal paths in Robo1;Robo2 double-mutant mice. $\boldsymbol{A}-\boldsymbol{F}$, Coronal sections through the diencephalon of E18.5 fetuses showing calretinin immunohistochemistry in wild-type $(\boldsymbol{A}, \boldsymbol{D})$ and Robo1; Robo2 double-mutant mice $(\boldsymbol{B}, \boldsymbol{C}, \boldsymbol{E}, \boldsymbol{F})$. Note the abnormal invasion of thalamocortical fibers into the hypothalamus ( $\boldsymbol{C}$, arrows). At more rostral levels, thalamocortical axons cross the ventral midline $(\boldsymbol{F}$, arrowheads) below the additional abnormal cross of corticofugal fibers $(\boldsymbol{E}$, arrow). $\mathbf{G}-\mathbf{I}, \mathbf{L}$, Coronal sections through the diencephalon of E18.5 embryos with Dil implanted in the dorsal thalamus (dTh), showing Dil axons abnormally entering the hypothalamus in Robo1;Robo2 double-mutant mice $(\boldsymbol{H}, \boldsymbol{I}) . \boldsymbol{J}, \boldsymbol{K}$, Very few thalamic axons reach the cortex in Robo1; Robo2 double-mutant mice. $M, N$, The schemas summarize the pathways followed by thalamocortical axons in wild-type $(\boldsymbol{M})$ and Robo1;Robo2 double-mutant mice $(\boldsymbol{N})$. Str, Striatum; VMH, ventromedial hypothalamic

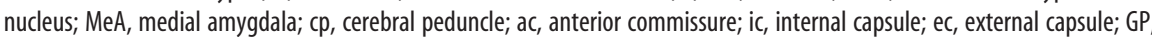
globus pallidus; Rt, reticular thalamic nucleus; MPO, medial preoptic area; hc, hippocampal commissure; $H$, hippocampus, $A H_{\text {, }}$ anterior hypothalamus; VM, ventromedial nucleus. Scale bars: $A, B, D, E, 300 \mu \mathrm{m} ; \boldsymbol{C}, \boldsymbol{F}, 200 \mu \mathrm{m} ; \boldsymbol{G}-\mathbf{I}, 1 \mathrm{~mm} ; \boldsymbol{J}-\mathbf{L}, 200 \mu \mathrm{m}$. is conceivable that heparan sulfate may also contribute along with Slit/Robo signaling to the guidance of these major forebrain projections.

\section{Concluding remarks}

The present results, along with our previous work on the analysis of Slit mutants (Bagri et al., 2002), demonstrate that Slit/Robo interactions play a crucial role in the guidance of some of the most prominent axonal tracts in the mammalian forebrain. Through a mechanism that involves the repulsion of growing axons (Brose et al., 1999; Kidd et al., 1999; Li et al., 1999), Slits intervene in multiple aspects in the development of major connections in the mammalian forebrain. These functions appear to be mediated mostly or exclusively by Robo1 and Robo2, because the forebrain phenotype of Robol; Robo2 double mutants looks highly similar, and possibly identical to the Slit1;Slit2 double-mutant phenotype. Furthermore, Robo1 and Robo 2 have mostly redundant roles in this process. Future studies will aim to reveal how Robo1 and Robo2 receptors are specifically regulated in distinct forebrain axonal tracts and how these receptors may interact with other guidance cues to control their final targeting.

\section{References}

Andrews W, Liapi A, Plachez C, Camurri L, Zhang J, Mori S, Murakami F, Parnavelas JG, Sundaresan V, Richards LJ (2006) Robol regulates the development of major axon tracts and interneuron migration in the forebrain. Development 133:2243-2252.

Auladell C, Pérez-Sust P, Supèr H, Soriano E (2000) The early development of thalamocortical and corticothalamic projections in the mouse. Anat Embryol 201:169-179.

Bagri A, Marín O, Plump AS, Mak J, Pleasure SJ, Rubenstein JL, Tessier-Lavigne M (2002) Slit proteins prevent midline crossing and determine the dorsoventral position of major axonal pathways in the mammalian forebrain Neuron 33:233-248.

Braisted JE, Tuttle R, O'Leary DD (1999) Thalamocortical axons are influenced by chemorepellent and chemoattractant activities localized to decision points along their path. Dev Biol 208:430-440.

Braisted JE, Catalano SM, Stimac R, Kennedy TE, Tessier-Lavigne M, Shatz CJ, O'Leary DD (2000) Netrin-1 promotes thalamic axon growth and is required for proper development of the thalamocortical projection. J Neurosci 20:5792-5801.

Brose K, Bland KS, Wang KH, Arnott D, Henzel W, Goodman CS, Tessier-Lavigne M, Kidd $\mathrm{T}$ (1999) Slit proteins bind Robo receptors and have an evolutionarily conserved role in repulsive axon guidance. Cell 96:795-806.

De Carlos JA, O'Leary DD (1992) Growth and targeting of subplate axons and establishment of major cortical pathways. J Neurosci 12:1194-1211. 
Wild-type

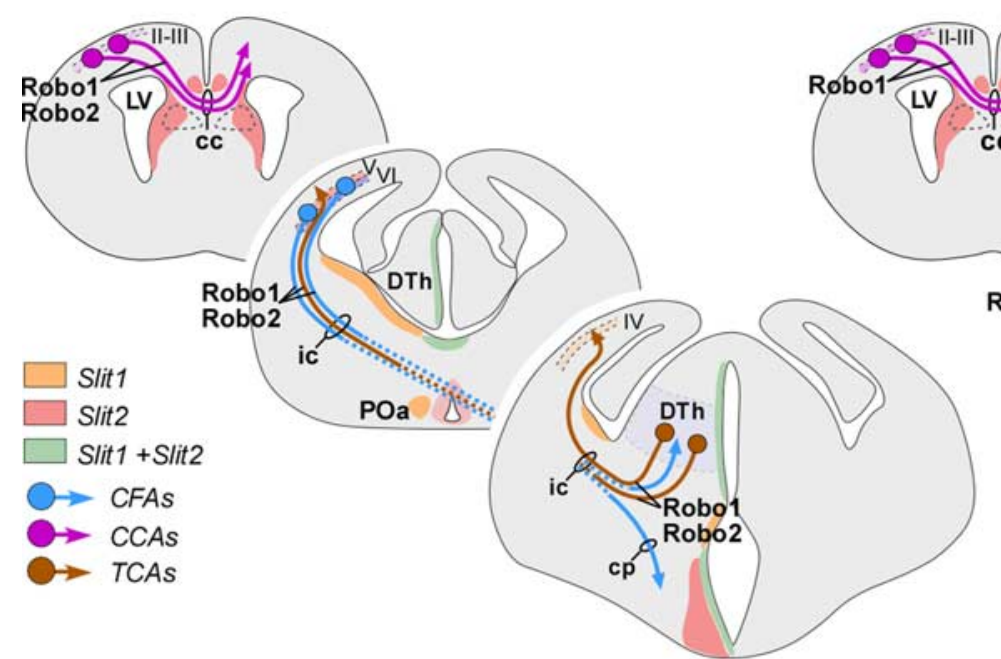

\section{Robo2 -}

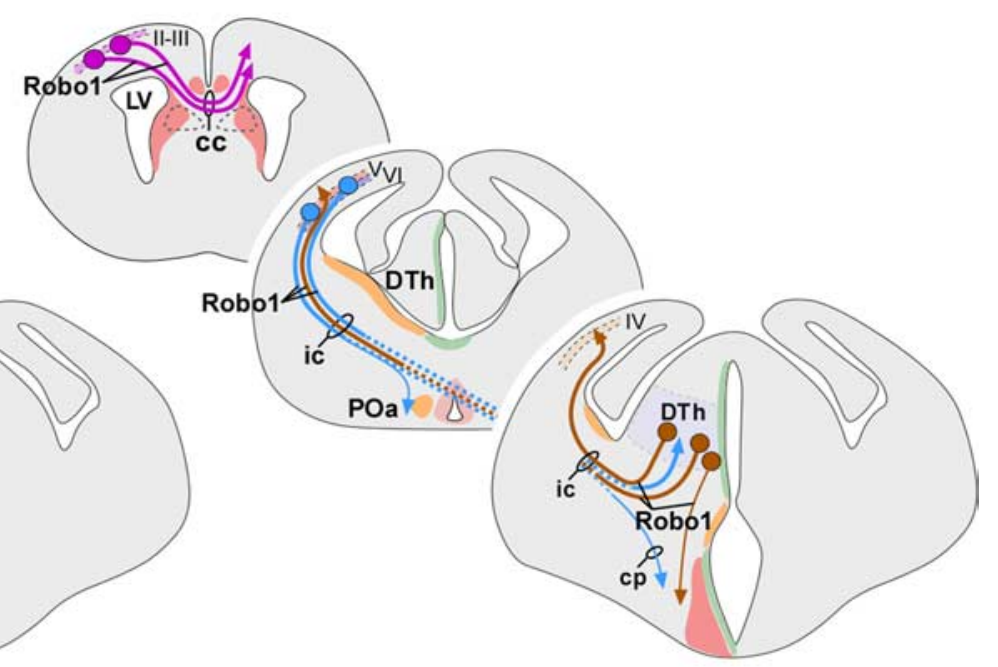

Slit2 $\%$

Slit1 ${ }^{-/} ;$Slit2 $^{\%}$ or Robo1 $\%$;Robo2 $2^{\%}$

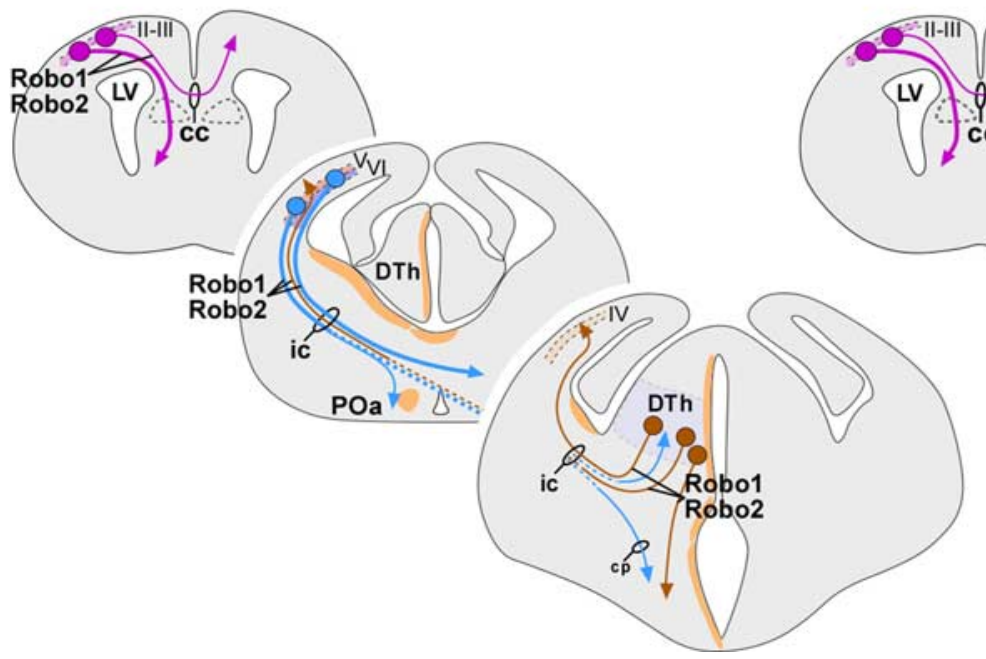

Figure 11. Schematic summarizing axonal defects in the Slit and Robo mutants in relation to regions of Slit action and Robo expression. Slit2 acts in ventral and ventrolateral domains, and Slit1 action is limited to medial areas. In wild-type animals, Slit2 prevents Robo-expressing axons from entering ventral regions and also prevents the axons from coursing medially. Loss of Slit1 does not have an impact on the axonal trajectories because of the continued presence of Slit2. However, loss of Slit2 allows the axons to project ventrally and medially, potentially in response to positive cues from these areas. Mice lacking Robo2 have a less severe phenotype than the one observed in Slit $2^{-1-}$ because of the presence of Robo 1 in those axonal tracts. Only a few corticofugal axons are misrouted from their normal route at the ventral telencephalon. Loss of Robo1 and Robo2 mimics the phenotype observed in mice lacking both Slit1 and Slit2, and allows axons to travel ventrally and medially and to approach and cross the midline. LV, Lateral ventricle; cc, corpus callosum; DTh, dorsal thalamus; ic, internal capsule; cp, cortical plate; P0a, anterior preoptic area; II-VI, cortical layers.

Dufour A, Seibt J, Passante L, Depaepe V, Ciossek T, Frisen J, Kullander K, Flanagan JG, Polleux F, Vanderhaeghen P (2003) Area specificity and topography of thalamocortical projections are controlled by ephrin/Eph genes. Neuron 39:453-465.

Grieshammer U, Le M, Plump AS, Wang F, Tessier-Lavigne M, Martin GR (2004) SLIT2-mediated ROBO2 signaling restricts kidney induction to a single site. Dev Cell 6:709-717.

Hao JC, Yu TW, Fujisawa K, Culotti JG, Gengyo-Ando K, Mitani S, Moulder G, Barstead R, Tessier-Lavigne M, Bargmann CI (2001) C. elegans slit acts in midline, dorsal-ventral, and anterior-posterior guidance via the SAX-3/Robo receptor. Neuron 32:25-38.

$\mathrm{Hu} \mathrm{H}$ (2001) Cell-surface heparan sulfate is involved in the repulsive guidance activities of Slit2 protein. Nat Neurosci 4:695-701.

Hutson LD, Chien CB (2002) Pathfinding and error correction by retinal axons: the role of astray/robo2. Neuron 33:205-217.

Inatani M, Irie F, Plump AS, Tessier-Lavigne M, Yamaguchi Y (2003) Mammalian brain morphogenesis and midline axon guidance require heparan sulfate. Science 302:1044-1046.
Jones L, López-Bendito G, Gruss P, Stoykova A, Molnar Z (2002) Pax6 is required for the normal development of the forebrain axonal connections. Development 129:5041-5052.

Kidd T, Bland KS, Goodman CS (1999) Slit is the midline repellent for the robo receptor in Drosophila. Cell 96:785-794.

Kinnunen A, Niemi M, Kinnunen T, Kaksonen M, Nolo R, Rauvala H (1999) Heparan sulphate and HB-GAM (heparin-binding growth-associated molecule) in the development of the thalamocortical pathway of rat brain. Eur J Neurosci 11:491-502.

Kolodkin AL, Levengood DV, Rowe EG, Tai YT, Giger RJ, Ginty DD (1997) Neuropilin is a semaphorin III receptor. Cell 90:753-762.

Lee JS, von der Hardt S, Rusch MA, Stringer SE, Stickney HL, Talbot WS, Geisler R, Nusslein-Volhard C, Selleck SB, Chien CB, Roehl H (2004) Axon sorting in the optic tract requires HSPG synthesis by ext2 (dackel) and extl3 (boxer). Neuron 44:947-960.

Leighton PA, Mitchell KJ, Goodrich LV, Lu X, Pinson K, Scherz P, Skarnes WC, Tessier-Lavigne M (2001) Defining brain wiring patterns and mechanisms through gene trapping in mice. Nature 410:174-179. 
Li HS, Chen JH, Wu W, Fagaly T, Zhou L, Yuan W, Dupuis S, Jiang ZH, Nash W, Gick C, Ornitz DM, Wu JY, Rao Y (1999) Vertebrate slit, a secreted ligand for the transmembrane protein roundabout, is a repellent for olfactory bulb axons. Cell 96:807-818.

Liang Y, Annan RS, Carr SA, Popp S, Mevissen M, Margolis RK, Margolis RU (1999) Mammalian homologues of the Drosophila slit protein are ligands of the heparan sulfate proteoglycan glypican-1 in brain. J Biol Chem 274:17885-17892.

Long H, Sabatier C, Ma L, Plump A, Yuan W, Ornitz DM, Tamada A, Murakami F, Goodman CS, Tessier-Lavigne M (2004) Conserved roles for Slit and Robo proteins in midline commissural axon guidance. Neuron 42:213-223.

López-Bendito G, Molnár Z (2003) Thalamocortical development: how are we going to get there? Nat Rev Neurosci 4:276-289.

López-Bendito G, Chan CH, Mallamaci A, Parnavelas J, Molnar Z (2002) Role of Emx2 in the development of the reciprocal connectivity between cortex and thalamus. J Comp Neurol 451:153-169.

López-Bendito G, Cautinat A, Sánchez JA, Bielle F, Flames N, Garratt AN, Talmage DA, Role L, Charnay P, Marín O, Garel S (2006) Tangential neuronal migration controls axon guidance: a role for Neuregulin-1 on thalamocortical axon navigation. Cell 125:127-142.

Marillat V, Cases O, Nguyen Ba-Charvet KT, Tessier-Lavigne M, Sotelo C, Chédotal A (2001) Spatio-temporal expression patterns of slit and robo genes in the rat brain. J Comp Neurol 442:130-155.

McConnell SK, Ghosh A, Shatz CJ (1989) Subplate neurons pioneer the first axon pathway from the cerebral cortex. Science 245:978-982.

Molnár Z, Adams R, Goffinet AM, Blakemore C (1998) The role of the first postmitotic cortical cells in the development of thalamocortical innervation in the reeler mouse. J Neurosci 18:5746-5765.

Métin C, Godement P (1996) The ganglionic eminence may be an intermediate target for corticofugal and thalamocortical axons. J Neurosci 16:3219-3235.

Métin C, Deléglise D, Serafini T, Kennedy TE, Tessier-Lavigne M (1997) A role for netrin-1 in the guidance of cortical efferents. Development 124:5063-5074.

Nguyen Ba-Charvet KT, Brose K, Ma L, Wang KH, Marillat V, Sotelo C, Tessier-Lavigne M, Chedotal A (2001) Diversity and specificity of actions of Slit2 proteolytic fragments in axon guidance. J Neurosci 21:4281-4289.

Nguyen Ba-Charvet KT, Plump AS, Tessier-Lavigne M, Chedotal A (2002) Slit 1 and slit2 proteins control the development of the lateral olfactory tract. J Neurosci 22:5473-5480.

Plump AS, Erskine L, Sabatier C, Brose K, Epstein CJ, Goodman CS, Mason CA, Tessier-Lavigne M (2002) Slit1 and Slit2 cooperate to prevent premature midline crossing of retinal axons in the mouse visual system. Neuron 33:219-232.

Price DJ, Kennedy H, Dehay C, Zhou L, Mercier M, Jossin Y, Goffinet AM, Tissir F, Blakey D, Molnar Z (2006) The development of cortical connections. Eur J Neurosci 23:910-920.
Rajagopalan S, Nicolas E, Vivancos V, Berger J, Dickson BJ (2000) Crossing the midline: roles and regulation of Robo receptors. Neuron 28:767-777.

Richards LJ, Koester SE, Tuttle R, O'Leary DD (1997) Directed growth of early cortical axons is influenced by a chemoattractant released from an intermediate target. J Neurosci 17:2445-2458.

Richards LJ, Plachez C, Ren T (2004) Mechanisms regulating the development of the corpus callosum and its agenesis in mouse and human. Clin Genet 66:276-289.

Ronca F, Andersen JS, Paech V, Margolis RU (2001) Characterization of Slit protein interactions with glypican-1. J Biol Chem 276:29141-29147.

Sabatier C, Plump AS, Le M, Brose K, Tamada A, Murakami F, Lee EY, Tessier-Lavigne M (2004) The divergent Robo family protein rig-1/ Robo3 is a negative regulator of slit responsiveness required for midline crossing by commissural axons. Cell 117:157-169.

Schaeren-Wiemers N, Gerfin-Moser A (1993) A single protocol to detect transcripts of various types and expression levels in neural tissue and cultured cells: in situ hybridization using digoxigenin-labelled cRNA probes. Histochemistry 100:431-440.

Serafini T, Colamarino SA, Leonardo ED, Wang H, Beddington R, Skarnes WC, Tessier-Lavigne M (1996) Netrin-1 is required for commissural axon guidance in the developing vertebrate nervous system. Cell $87: 1001-1014$.

Shu T, Richards LJ (2001) Cortical axon guidance by the glial wedge during the development of the corpus callosum. J Neurosci 21:2749-2758.

Shu T, Sundaresan V, McCarthy MM, Richards LJ (2003) Slit2 guides both precrossing and postcrossing callosal axons at the midline in vivo. J Neurosci 23:8176-8184.

Simpson JH, Bland KS, Fetter RD, Goodman CS (2000) Short-range and long-range guidance by Slit and its Robo receptors: a combinatorial code of Robo receptors controls lateral position. Cell 103:1019-1032.

Sundaresan V, Mambetisaeva E, Andrews W, Annan A, Knoll B, Tear G, Bannister L (2004) Dynamic expression patterns of Robo (Robol and Robo2) in the developing murine central nervous system. J Comp Neurol 468:467-481.

Torii M, Levitt P (2005) Dissociation of corticothalamic and thalamocortical axon targeting by an EphA7-mediated mechanism. Neuron 48:563-575.

Tuttle R, Nakagawa Y, Johnson JE, O'Leary DD (1999) Defects in thalamocortical axon pathfinding correlate with altered cell domains in Mash-1deficient mice. Development 126:1903-1916.

Whitford K, Marillat V, Stein E, Goodman C, Tessier-Lavigne M, Chedotal A, Ghosh A (2002) Regulation of cortical dendrite development by SlitRobo interactions. Neuron 33:47-61.

Yuan W, Zhou L, Chen JH, Wu JY, Rao Y, Ornitz DM (1999) The mouse SLIT family: secreted ligands for ROBO expressed in patterns that suggest a role in morphogenesis and axon guidance. Dev Biol 212:290-306.

Zheng B, Ho C, Li S, Keirstead H, Steward O, Tessier-Lavigne M (2003) Lack of enhanced spinal regeneration in Nogo-deficient mice. Neuron $38: 213-224$. 